\title{
VEINTE AÑOS DE RELACIONES ESTRATÉGICAS DE LA UNIÓN EUROPEA CON AMÉRICA LATINA Y EL CARIBE (1999-2019): ANÁLISIS DE LA EVOLUCIÓN DE SUS “TRES PILARES” FUNDAMENTALES
}

\author{
TWENTY YEARS OF STRATEGIC RELATIONS BETWEEN \\ THE EUROPEAN UNION AND LATIN AMERICA AND THE \\ CARIBBEAN (1999-2019): ANALYSIS OF THE EVOLUTION \\ OF ITS "THREE PILLARS"
}

VINGT ANNÉES DE RAPPORTS STRATÉGIQUES DE L'UNION EUROPÉENNE AVEC L'AMÉRIQUE LATINE ET LES CARAÏBES (1999-2019): UNE ANALYSE DE L'ÉVOLUTION DE LEURS «TROIS PILIERS» PRINCIPAUX

\author{
IVÁN GONZÁlez SARRo \\ Instituto Universitario de Investigación en \\ Estudios Latinoamericanos (IELAT) \\ ivan.gonzalezs@edu.uah.es
}

RESUMEN: El artículo se centra en las relaciones birregionales entre la Unión Europea (UE) y América Latina y el Caribe (ALC) en el marco de la política exterior europea. Su objetivo central es examinar la evolución de los "tres pilares" fundamentales en torno a los cuales se han articulado tales relaciones: el diálogo político, la cooperación y el comercio -en un sentido más o menos amplio-, desde 1999, año en que se creó la "Asociación Estratégica" que encauza las relaciones birregionales. La hipótesis central interpretativa del trabajo es que ALC no ha representado una prioridad en el marco de la política exterior de la UE. Las relaciones se han mantenido con cierta asimetría y, a pesar de que se han logrado avances en algunos temas relevantes, en ninguno de los "tres pilares" los resultados han sido notables. Esto no ha sido así desde el punto de vista del desarrollo y la mejora de las condiciones económicas, sociales y políticas en Latinoamérica, ni desde el de la propia influencia europea en esta región. Las relaciones UE-AL han pasado por alto algunos temas considerados clave, como las migraciones, la cooperación en materia educati- 
va, la gestión de la deuda externa, entre otros. Finalmente, se defiende la idea de que pueden y deben profundizarse estas relaciones, y de que la región de ALC puede constituir un aliado estratégico imprescindible de la UE.

Palabras clave: relaciones Unión Europea y América Latina; diálogo político; cooperación; comercio; Unión Europea; América Latina.

AbSTRACT: The article focuses on bi-regional relations between the European Union and Latin America and the Caribbean within the framework of European foreign policy. Its basic objective is to examine the evolution of the fundamental "three pillars" around which these relations have been articulated: political dialogue, cooperation and trade -in a more or less broad sense- since 1999, in which the "Strategic Association" was formed, which channels bi-regional relations. The central interpretative hypothesis of the work is that Latin America has not been a priority in the framework of the foreign policy of the European Union. Relations have been maintained with a degree of asymmetry and, although progress has been made on some relevant issues, it is argued that none of the "three pillars" have seen substantial results, neither from the point of view of the development and improvement of economic, social and political conditions in Latin America, nor from that of European influence in the region. It is argued that in EU-LAC relations some issues that are considered key, such as migration, cooperation in education, and external debt management, among others, have been ignored. Finally, it is suggested that EU-LAC relations can and should be deepened and that the Latin American region can be an indispensable strategic ally of the European Union.

Keywords: European Union-Latin America relations; political dialogue; cooperation; trade; European Union; Latin America.

\section{Traducción de Gonzalo Celorio Morayta}

Résumé: L'article est consacré aux rapports de l'Union Européenne avec l'Amérique latine et les Caraïbes dans le cadre de la politique étrangère européenne. Le but principal est d'examiner l'évolution de «trois piliers» essentiels, sur lesquels s'appuient ces rapports: le dialogue politique, la coopération et le commerce (au sens large), grâce auxquels une association stratégique a pris forme depuis 1999 pour guider les relations entre les deux régions. L'hypothèse est que la politique étrangère de l'Union Européenne n'a guère accordé la priorité à l'Amérique latine. Les liens entre elles demeurent asymétriques, sans résultats 
remarquables, malgré des progrès dans les conditions économiques, sociales et politiques de l'Amérique latine, pour ne rien dire de l'influence européenne sur cette région-ci. Même des sujets essentiels, tels que la migration, la coopération pour l'éducation ou la gestion de la dette étrangère, parmi d'autres, ont été négligés. L'article soutient l'idée que les relations en question peuvent et doivent s'approfondir, et que l'Amérique latine serait capable de devenir un allié stratégique de l'Union Européenne.

Mots clefs: Relations Union Européenne-Amérique latine; dialogue politique; coopération; commerce; Union Européenne; Amérique latine.

Traducción de Bernardo Mabire

Fecha de recepción: mayo de 2019

Fecha de aceptación: abril de 2020

E n junio de 1999 se celebró la I Cumbre entre la Unión Europea (UE) y América Latina y el Caribe (ALC) en Río de Janeiro. En ésta se dio un salto cualitativo importante en las relaciones birregionales con la puesta en marcha de la "Asociación Estratégica" entre la UE y ALc.

Al cumplirse 20 años de la Cumbre de Río y de funcionamiento del Acuerdo de Asociación Estratégica, que ha encauzado las relaciones birregionales desde entonces, parece que puede resultar pertinente esbozar un balance de las relaciones ALC-UE. Este trabajo se centra en este tema.

Lo primero que cabe puntualizar es que, desde la perspectiva europea, resulta usual referirse a la "historia común" de la UE y ALC, que los ha llevado a ser "aliados naturales unidos por fuertes vínculos históricos, culturales y económicos, así como por una convergencia de valores básicos y principios". ${ }^{1}$ Lo cier-

${ }^{1}$ Comisión Europea, La asociación estratégica entre la Unión Europea, América Latina y el Caribe: un compromiso común, Luxemburgo: Oficina de Publicaciones Oficiales de las Comunidades Europeas, 2008, p. 5. 
to es que América Latina no había figurado en la agenda externa de la Comunidad Europea (CE) hasta principios de los años ochenta, cuando los europeos se implicaron en el proceso de paz centroamericano. Éste fue el primer paso que acercó a la cE a América Latina, cuando por vez primera Latinoamérica apareció en la agenda de la CE. Por otro lado, éste "fue uno de los primeros proyectos de política exterior que los miembros de la CE emprendieron en conjunto, por medio de lo que se conocía entonces como la Cooperación Política Europea (CPE), antecesora de la Política Exterior y de Seguridad Común (PESC)", tal como explica Ruano. ${ }^{2}$ Hasta mediados de los años noventa, las relaciones de la uE con los países latinoamericanos se limitaron a acuerdos de cooperación, asistencia financiera y tecnológica, y preferencias comerciales en el marco del Sistema Generalizado de Preferencias (SPG). Sin embargo, en aquellos años noventa, (caracterizados por haber sido el escenario más propicio de la posguerra fría, por el auge del regionalismo latinoamericano y el desarrollo de la Política Exterior y de Seguridad Común, PESC), se afirmó desde la UE una estrategia interregional que respondía de manera diferenciada al nuevo mapa de la integración latinoamericana.

Como se ha dicho, en 1999 -en la Cumbre de Río de Janeiro- se creó una "asociación estratégica". Este Acuerdo de Asociación Estratégica ALC-UE ha contribuido a dar forma a las relaciones bilaterales que han mantenido los 60 países -27 de la ue y 33 de ALC- que integran dicha Asociación. ${ }^{3}$

Esta estrategia, que ha cumplido ya veinte años, dio paso a un diálogo político birregional de alto nivel, a través de las Cumbres entre la UE y ALC. Incluyó también una cooperación al desarrollo más amplia y diversificada, así como la propuesta de

${ }^{2}$ Lorena Ruano, "La Unión Europea y América Latina: Breve historia de la relación birregional", Revista Mexicana de Política Exterior, núm. 112 (2018), pp. 73-74.

${ }^{3}$ José Antonio Sanahuja, Hacia un nuevo marco de relaciones entre la Unión Europea y América Latina y el Caribe, Hamburgo, Fundación EU-LAC, 2013, p. 6. 
una red de acuerdos de asociación de carácter bilateral o plurilateral que cubrían el conjunto de América Latina y el Caribe. ${ }^{4}$

Las sucesivas generaciones de estos acuerdos de cooperación -que han ido suponiendo realmente importantes saltos adelante en las relaciones birregionales, con el fin de adaptarlos a los diferentes escenarios e intereses tanto europeos como latinoamericanos- han adaptado el modelo de relaciones de la UE con ALc. En todo caso, la institucionalización de estas relaciones ha resultado vital para ambas regiones. En este sentido, Martín afirma que:

Para la UE, su relación política con AL es necesaria para una mayor consolidación de su PESC y su inserción en los asuntos mundiales como un "actor" internacional, más allá de su área tradicional de influencia. A su vez, para América Latina, las relaciones con Europa refuerzan su propio proceso de integración y democratización. Simultáneamente, los latinoamericanos intentan tener relaciones comerciales y de inversión con un mayor énfasis en el desarrollo que aquellas que se pueden obtener con Estados Unidos, las cuales aún están más marcadas por un tenor de seguridad. ${ }^{5}$

A pesar de todo ello, según algunos autores, la uE no ha variado significativamente su estrategia en las relaciones con ALC, razón por la cual ha quedado esa estrategia, como lo han destacado Freres y Sanahuja, "fuera de juego respecto de las realidades e intereses europeos y latinoamericanos en la actualidad". ${ }^{6}$ Afirman otros estudiosos que el modelo de relaciones birregionales "ha quedado obsoleto desde princi-

${ }^{4}$ Ibid., p. 17.

${ }^{5}$ Carlos D. Martín, "Las relaciones América Latina-Unión Europea: antecedentes de la importancia e institucionalización del diálogo político”, Revista de Ciencia Política, vol. xxıI, núm. 2, 2002, p. 48.

${ }^{6}$ Christian Freres y José Antonio Sanahuja, "Hacia una nueva estrategia en las relaciones Unión Europea-América Latina”, en C. Freres y J.A. Sanahuja (coords.), América Latina y la Unión Europea. Estrategias para una asociación necesaria, Barcelona, Icaria, 2006, pp. 26-29. 
pios del siglo XxI, como consecuencia de las profundas transformaciones experimentadas por los escenarios mundial, europeo y latinoamericano". ${ }^{7}$ Existe la percepción de otros respecto a que "el enfoque tradicional con el que se han abordado las relaciones entre la UE y ALC requiere una renovación profunda". 8

Ciertamente, en los últimos años, en Europa y en América Latina han surgido hechos relevantes que inciden en la política latinoamericana de la UE. En Europa, la crisis de refugiados e inmigrantes, la creciente presencia y auge electoral de partidos extremistas en algunos países europeos, la salida del Reino Unido de la UE, el conflicto en Ucrania y el terrorismo, sin duda han afectado la acción y políticas comunitarias europeas en Latinoamérica. De la misma forma que los cambios políticos en Brasil y Argentina, la delicada crisis en Venezuela, el restablecimiento de las relaciones formales de Cuba con Estados Unidos, el proceso de paz en Colombia y dos reuniones entre la Comunidad de Estados Latinoamericanos y Caribeños y la UE han modificado las lógicas de las políticas latinoamericanas de la UE. ${ }^{9}$ Además, en la uE se han producido otros cambios que han afectado a las relaciones con ALC. Sucesivas ampliaciones introdujeron una mayor heterogeneidad en ésta, afectando el interés del conjunto de la Unión sobre América Latina y el modo en que en las instancias comunitarias se percibe a la región latinoamericana. ${ }^{10}$

${ }^{7}$ Celestino del Arenal, Las relaciones entre la UE y América Latina: ¿abandono del regionalismo y apuesta por una nueva estrategia de carácter bilateralista?, Documento de Trabajo 36/2009, Madrid, Real Instituto El Cano, 2009, pp. 3-4.

${ }^{8}$ José Antonio Alonso, "Hacia una nueva estrategia UE-América Latina: notas para el debate”, en Foro eurolatinoamericano de centros de análisis. Diálogo UE-ALC. Debate y Conclusiones, Madrid, Fundación Carolina, 2010, p. 97.

${ }^{9}$ Giovanni Molano-Cruz (comp.), La Unión Europea en América Latina y el Caribe (1945-2012). Lógicas y políticas de un actor global, Bogotá, Universidad Sergio Arboleda, 2015, pp. 15-16.

${ }^{10}$ Carlos Malamud, Las relaciones entre la Unión Europea y América Latina en el siglo XXI: entre el voluntarismo y la realidad, Documento de trabajo núm. 6, Plataforma Democrática, 2010, p. 6. 
Igualmente, los cambios en el escenario internacional desde la Primera Cumbre alcue, en 1999, han condicionado el diálogo birregional, sin duda. Los atentados del 11-S y la posterior invasión de Irak afectaron en gran medida las tendencias multilateralistas existentes en el planeta. Posteriormente, la crisis económica y financiera internacional tendió a dar un papel más protagónico a los Estados, además de que obligó a diseñar un marco para la gobernanza global, en el que el G-20 tuvo cierto protagonismo. ${ }^{11}$

Por otro lado, si, como afirma Martín, "Europa ha estado atenta a los cambios en América Latina y, a su vez, esta última ha buscado constantemente establecer lazos políticos, económicos y culturales con Europa, que le permitan contrapesar la influencia de Estados Unidos, particularmente a partir del último siglo", ${ }^{12}$ la presencia de nuevas potencias económicas y políticas de carácter global en la región latinoamericana está afectando las relaciones birregionales. Según lo explica Alonso, a la presencia tradicional en América Latina de la Ue y de Estados Unidos, "se han unido en los últimos años el activismo económico de China, ${ }^{13}$ con alta capacidad para promover inversiones y generar una demanda internacional para las exportaciones (especialmente primarias) de la región; y el menos evidente, pero perceptible,

11 Ibid, p. 8.

${ }^{12}$ Martín, art. cit., p. 46.

${ }^{13}$ La expansión del comercio entre China y América Latina ha sido muy notable, al aumentar de 10000 millones de dólares a más de 257000 millones entre 2000 y 2014. China sola representa alrededor de la mitad del comercio entre Asia y América Latina y se ha convertido en el segundo mayor proveedor de importaciones de la región y el tercer destino principal de sus exportaciones. Según la Comisión Económica para América Latina y el Caribe (CEPAL), las importaciones de la región procedentes de China aumentaron desde poco más de 2\% a 16\% entre 2000 y 2014, mientras que las exportaciones se incrementaron de $1 \%$ a $9 \%$ (cayendo desde el $10 \%$ en 2013). Así, en 2014, China y la uE representaron prácticamente el mismo porcentaje en el comercio de bienes de América Latina con el mundo ( $12.4 \%$ y $12.5 \%$, respectivamente); OCDE/CEPAL/ CAF, 2015 pp. 98-99. 
mayor activismo político de la Federación Rusa, especialmente presente en ámbitos estratégicos relacionados con la energía y la defensa", dotando a la región de "un panorama más plural de opciones a la hora de construir sus relaciones internacionales". 14

En suma, las expectativas y la valoración de la relación birregional y de cada una de sus partes han experimentado cambios significativos. El objeto básico de este trabajo es hacer un balance de estos veinte años de la "Asociación Estratégica” ALC-UE, analizando la evolución de las tres dimensiones o "tres pilares" básicos en torno a los cuales se articularon las relaciones birregionales, ya desde la citada primera Cumbre en Río, esto es: diálogo político, relaciones económicas y comerciales y cooperación.

De entrada, son muchas las cuestiones que podrían plantearse: ¿Qué avances y logros se han producido en las relaciones entre la UE y ALC en el periodo bajo análisis? ¿Qué problemas se han planteado en las relaciones? ¿Cuál es la situación actual de éstas? ¿A qué grado de progreso y profundización se ha llegado en las relaciones? ¿Qué factores han incidido en las relaciones birregionales? ¿Qué balance general puede hacerse?

El propósito último del trabajo tan sólo es acercarnos y explorar la respuesta a estas preguntas.

Nuestra hipótesis central interpretativa es que América Latina y el Caribe no han representado una prioridad en el marco de la política exterior de la Unión Europea. Las relaciones han mantenido cierta asimetría y, a pesar de que se han alcanzado avances en algunos temas relevantes, sostenemos que los resultados no han sido notables en ninguno de los "tres pilares", y no ya desde el punto de vista del desarrollo y la mejora de las condiciones económicas, sociales y políticas en Latinoamérica, sino también desde el de la propia influencia europea en esta región. Planteamos que en las relaciones UE-ALC se han obviado algunos temas

${ }^{14}$ Alonso, art. cit., p. 94. 
que consideramos clave, como las migraciones, la cooperación en materia educativa, la gestión de la deuda externa, entre otros. Finalmente, defendemos la idea de que pueden y deben profundizarse las relaciones UE-ALC y que la región de ALC puede constituir un aliado estratégico imprescindible de la UE.

El trabajo se organiza del siguiente modo. En el siguiente apartado se realiza un análisis de la evolución, entre 1999 y 2019, de cada uno de los "tres pilares" fundamentales en los que se han basado las relaciones UE-ALC. Las conclusiones más relevantes del estudio se condensan en el apartado tercero.

ANÁlisis de los “TRES PILARES” DE LAS RELACIONES DE LA UE-AL

Resulta común analizar las relaciones UE-ALC en torno a los "tres pilares" que las articularían: el diálogo político, la cooperación y el comercio. Estos tres ejes temáticos fueron establecidos en la Cumbre de Río de Janeiro de 1999. En el capítulo político, el gran mensaje de la Cumbre fue el lanzamiento de lo que se denominó "la Asociación Estratégica Birregional”, idea-fuerza que partía de la constatación de la pertenencia de ambas regiones a un mismo universo cultural y de valores. En el plano económico, la Conferencia de Río de Janeiro, aunque desde el principio quedó muy claro que no era una instancia para la negociación comercial, sirvió para impulsar la negociación del acuerdo de asociación con México y para confirmar la disposición de la uE a negociar, asimismo, sendos acuerdos de asociación con el Mercosur y con Chile. Finalmente, en el ámbito de la cooperación, se definió todo un catálogo de posibles áreas temáticas para desarrollar acciones conjuntas. En los siguientes apartados se analizan cada uno de estos "tres pilares". 


\section{El diálogo político}

Tal como lo señala Levi, el diálogo político es un mecanismo que ha implementado la UE en los acuerdos suscritos con ALC en los ámbitos regional, subregional y bilateral, para profundizar el nivel de sus relaciones en el marco de la política exterior y tratar aspectos que no serían considerados en acuerdos específicos de carácter comercial o en los relativos a la cooperación. El diálogo político es un elemento diferenciador en las relaciones que mantiene la UE a nivel birregional, en el marco de su política exterior. En efecto, los acuerdos que AL ha generado con otros actores internacionales (bilaterales o regionales) no tienen este componente, por lo menos no de forma específica como en el caso de los suscritos con la UE. ${ }^{15}$

Según lo explica Celestino del Arenal, el diálogo político entre la UE y ALC se sustenta, en una medida importante, en el acervo histórico y cultural existente entre ambas regiones, que les permite compartir valores y principios, y responde a la necesidad sentida por ambas partes de concertar estratégicamente posiciones comunes y reforzar su protagonismo en los distintos foros internacionales. Constituye, en este sentido, un importante instrumento de autonomía y diversificación de las relaciones internacionales de ambas regiones frente a Estados Unidos. Es, igualmente, un elemento fundamental de la pretendida "Asociación Estratégica Birregional". ${ }^{16}$

Este pilar de las relaciones birregionales ha generado diversas percepciones. Así, para algunos, el diálogo político es un mecanismo eficaz y diferenciador del esquema conven-

${ }^{15}$ Michel Levi Coral, "El diálogo político como pilar de las relaciones entre la Unión Europea y América Latina: reflexiones sobre su desarrollo y contenido", Oasis, núm. 12, Centro de Investigaciones y Proyectos Especiales, CIPE, Facultad de Finanzas, Gobierno y Relaciones Internacionales, Universidad Externado de Colombia, 2007, pp. 483-484.

${ }^{16}$ Celestino del Arenal, "Balance de la asociación estratégica entre la Unión Europea (UE) y los países de ALC", en Foro eurolatinoamericano de centros de análisis. Diálogo UE-ALC. Debate y Conclusiones, Madrid, Fundación Carolina, 2010, p. 34. 
cional de manejo de las relaciones bilaterales, que siempre es susceptible de mejorar; ${ }^{17}$ para otros, su contenido se ve afectado en la práctica por falta de capacidad ejecutiva y exceso de declaraciones, al igual que por un desconocimiento de cada una de las partes de las competencias y mecanismos que hacen posible la implementación de los acuerdos. ${ }^{18}$

El inicio del diálogo político entre ambas regiones hay que situarlo en 1984, con la puesta en marcha de un diálogo birregional, a través del proceso de San José para la pacificación de Centroamérica. Esa experiencia permitió la institucionalización del diálogo uE-Grupo de Río, en 1990, al que siguieron el establecimiento de toda una serie de foros de diálogo independientes, subregionales y bilaterales, con la can, Mercosur, Chile y México, que se sumaron a los ya existentes con Centroamérica y Grupo de Río. ${ }^{19}$ Es decir, el diálogo político entre las dos regiones se ha dado bajo diferentes instancias y canales.

Entre los esquemas de desarrollo del diálogo político, cabe referirse a los siguientes: el diálogo interparlamentario; los diálogos grupo a grupo de carácter regional (UE-Grupo de Río) y subregional (Centroamérica, Mercosur y Comunidad Andina, CAN); interregional en las cumbres de jefes de Estado y gobierno; y bilateral con Estados que han suscrito acuerdos de asociación de cuarta generación (México, Chile). No pueden dejar de considerarse otros esquemas de diálogo que se han generado en los últimos años, como es el diálogo institucionalizado con la sociedad civil que la uE ha mantenido desde 2002 con el objeto de contar con una visión diferente del estado de las relaciones birregionales. ${ }^{20}$ Es decir, a partir de la Cumbre ALC-UE de Río, en 1999, que inauguró un nuevo foro

17 Christian Freres et al. (ed.), ¿ Sirve el diálogo político entre la Unión Europea y América Latina?, Madrid, Fundación Carolina Cealci, 2007, p. 6.

18 Ramón Torrent, "Las relaciones Unión Europea-América Latina en los últimos diez años: el resultado de la inexistencia de una política. Un análisis empírico y esperanzado", unU-CRIs Occasional Papers 0-2005/10, Barcelona, Eularo/obreal, 2005, pp. 38-39.

19 Arenal, 2010, art. cit., p. 35.

${ }^{20}$ Levi, art. cit., pp. 484-485. 
de diálogo birregional al más alto nivel político, se fueron añadiendo progresivamente toda una serie de diálogos sectoriales, gubernamentales y no gubernamentales, que han enriquecido, al menos en teoría, la agenda del diálogo birregional. Al mismo tiempo, se abrieron también foros de diálogo bilateral con Brasil, a partir de la Asociación Estratégica, en 2007, y con Cuba, desde 2008. El 12 de diciembre de 2016, con el Acuerdo de Diálogo Político y de Cooperación (ADPC), la UE y Cuba abrieron un nuevo capítulo en su relación. Paralelamente, se fueron produciendo pasos para institucionalizar un diálogo político de alto nivel con Argentina. ${ }^{21}$

Hay que tener en cuenta en este contexto que, tal como señala Alemany, el análisis del diálogo UE-ALc pasa por la constatación de que desde la ue se desconfía de concertar posiciones con tantos países latinoamericanos al mismo tiempo, ya que ese mecanismo no es el más "eficiente", y se reclama el hecho de que ALC no tiene aún mecanismos claros para concertar posiciones en el ámbito multilateral. Pero también es verdad que, desde la UE, ALC es vista de forma muy ambigua, puesto que se seccionan los intereses comerciales. La UE negocia con ALC por países o regiones (y trata sus intereses en ese formato): México, Chile, Mercosur, CAN, América Central, y el Caribe se trata como parte de África-Caribe-Pacífico (ACP) y no de ALC. Este "seccionamiento", en la práctica, provoca que se aumenten las divisiones del continente (a través de ofertas diferenciadas de la UE), aunque en el discurso, la UE busca la "integración" de ALc. ${ }^{22}$

En función de todo ello, pueden sintetizarse los diferentes esquemas y mecanismos de diálogo con base en dos criterios que se cruzan: a) la diferenciación por regiones y países; y b) la clasificación por tipo de actores involucrados en el diálogo (véase cuadro 1).

${ }^{21}$ Arenal, 2010, art. cit., p. 35.

22 Cecilia Alemany, "Mecanismos de diálogo Unión Europea-América Latina", en Christian Freres et al. (ed.), ¿Sirve el diálogo político entre la Unión Europea y América Latina?, Madrid: Fundación Carolina CeAlcI, 2007, pp. 46-47. 


\section{Cuadro 1 \\ Esquemas y mecanismos de diálogo Unión Europea (UE)- América Latina y el Caribe (ALC)}

\begin{tabular}{|c|c|}
\hline Diferenciación por regiones & Clasificación por tipo de actores \\
\hline $\begin{array}{l}\text { Birregional: UE - ALC } \\
\text { — Reuniones UE -Grupo de Río } \\
\text { — Cumbres de presidentes y jefes de } \\
\text { Estado y de gobierno UE-ALC: } \\
\text { - Cumbre de Río (1999) } \\
\text { - Cumbre de Madrid (2002) } \\
\text { - Cumbre de Guadalajara (2004) } \\
\text { - Cumbre de Viena (2006) } \\
\text { - Cumbre de Lima (2008) } \\
\text { - Cumbre de Madrid (2010) } \\
\text { - Cumbres ue-CELAC } \\
\text { - Cumbre de Santiago de Chile (2013) } \\
\text { - Cumbre de Bruselas (2015) } \\
\text { - Cumbre de El Salvador (2017) }\end{array}$ & $\begin{array}{l}\text { Diálogos de alto nivel: } \\
\text { - Cumbres de presidentes y jefes de gobierno } \\
\text { - Diálogos sectoriales } \\
\text { - Reuniones de ministros }\end{array}$ \\
\hline $\begin{array}{l}\text { UE-subregiones: } \\
\text { — UE-Mercosur (según Acuerdo marco } \\
\text { interregional de 1995) } \\
\text { — UE-CAN (en el marco del Acuerdo de } \\
\text { Cooperación y Diálogo Político, } \\
\text { firmado en diciembre de 2003) } \\
\text { — UE-América Central }\end{array}$ & $\begin{array}{l}\text { Diálogos a nivel parlamentario: } \\
\text { - Conferencias interparlamentarias UE-AL } \\
\text { - Conferencias interparlamentarias UE-América } \\
\text { Central } \\
\text { - Conferencias interparlamentarias UE-CAN } \\
\text { - Conferencias interparlamentarias UE-México } \\
\text { - Conferencias interparlamentarias UE-Chile } \\
\text { - Conferencias interparlamentarias } \\
\quad \text { UE-MERCosuR }\end{array}$ \\
\hline $\begin{array}{l}\text { UE-países: } \\
\text { — UE-Chile (en el marco del Acuerdo } \\
\text { de Asociación, AA, vigente, suscrito } \\
\text { en 2000). } \\
\text { — UE-México (en el marco del Acuerdo } \\
\text { de Asociación (AA) vigente, suscrito } \\
\text { en 2002). } \\
\text { — UE-Brasil (a partir de 2007) } \\
\text { — UE-Cuba (a partir del Acuerdo de } \\
\text { Diálogo Político y de Cooperación } \\
\text { (ADPC) de } 12 \text { de diciembre de 2016) }\end{array}$ & $\begin{array}{l}\text { Diálogos con la sociedad civil (sc): } \\
\text { - I y II Conferencia UE- Mercosur y uE -Chile } \\
\text { (2000 y 2002) } \\
\text { — I y II Foro de Diálogo UE-México (2002 y } \\
\text { 2005) } \\
\text { — I Foro de Diálogo con la SC UE-CAN (2005) } \\
\text { - I Foro de Diálogo SC UE-América Central } \\
\text { sobre la integración regional (2004) } \\
\text { - Consultas a la sC en las Delegaciones en } \\
\text { AL sobre los borradores de las Notas de } \\
\text { Concepto País 2007-2013 }\end{array}$ \\
\hline
\end{tabular}




\section{CuAdro 1 (conclusión)}

\begin{tabular}{|l|l|}
\hline Diálogos propios de la Sc birregional: \\
- Cumbre Birregional de la Sociedad Civil \\
$\quad$ Organizada \\
- Cumbre Sindical Birregional \\
- cEs-Consejo Laboral Andino y Consejo \\
$\quad$ Empresarial Andino \\
- LAC-European Business Forum \\
- Foro de Negocios Mercosur-UE \\
- Redes de onG y redes académicas \\
- Etcétera
\end{tabular}

Fuente: elaboración propia, adaptado de Alemany, art. cit., p. 58.

No es posible detenernos a comentar cada uno de estos mecanismos de diálogo debido a límites en la extensión del presente artículo, pero merece la pena detenernos en algunos. El diálogo interparlamentario tiene más de cuarenta años de existencia y se ha desarrollado entre actores bien definidos: Parlamento Europeo y Parlamento Latinoamericano, Parlatino. Está institucionalizado, sus reuniones son periódicas y se celebran cada dos años. Constituyen la primera manifestación formal de diálogo político interregional. Los actores que participan en este diálogo no son de naturaleza y competencias similares. Así, el Parlamento Europeo es una institución de la UE, mientras que el Parlatino es un organismo intergubernamental que no tiene anclaje en ninguna entidad de integración y que tampoco tiene competencias concretas de ninguna índole. Tal vez ése sea el principal problema del Parlatino. Los resultados de este diálogo se han dado sobre todo en la promoción de la democracia y la paz en ALC, y promover la cooperación para el desarrollo en la región a través de los mecanismos de la Comunidad Europea. ${ }^{23}$

${ }^{23}$ Levi, art. cit., p. 485. 
Dentro de los "diálogos de alto nivel", los diálogos grupo a grupo de carácter regional, subregional y bilateral se han dado, en principio, en forma de reuniones ministeriales para tratar aspectos específicos de las relaciones, que no involucren negociación de tratados o de aspectos comerciales. Los diálogos subregionales a nivel ministerial se dan de forma colateral al diálogo ministerial institucionalizado entre la UE y el Grupo de Río, y en el margen de estas reuniones. ${ }^{24}$

El diálogo entre la UE y el Grupo de Río ${ }^{25}$ permitió contar con un foro regional que representase a AL, así como generar un diálogo institucionalizado, a partir de 1990, con la "Declaración de Roma", a través de una reunión ministerial bianual, cuya temática se ha centrado en la consolidación democrática, seguridad y respaldo a los procesos de paz en la región. Sin embargo, a raíz de la aparición de las cumbres birregionales de jefes de Estado y de gobierno, este mecanismo ha quedado superado, más aún cuando los temas a los que se ha referido tradicionalmente son privilegiados en otros marcos institucionales, como la Organización de Estados Americanos (OEA). ${ }^{26}$

El diálogo entre la UE y los entes de "integración subregional" (MERCOSUR, CAN y América Central) ha sido más estructurado, sobre todo a partir de los años noventa, con la suscripción de acuerdos de cooperación de "tercera generación”, en los que se incluyó el diálogo político como parte de la estructura de las relaciones a este nivel, y que generó un marco de reuniones a nivel ministerial para tratar aspectos de comercio y cooperación. ${ }^{27}$

${ }^{24}$ Alemany, art. cit., p. 51.

${ }^{25}$ Este Grupo fue creado en 1986, cuando los gobiernos de Argentina, Brasil, Colombia, Panamá, Perú, Uruguay y Venezuela adoptaron la "Declaración de Río de Janeiro". El Grupo de Río tiene tres niveles de diálogo: coordinadores nacionales, ministerial y presidencial. La Cumbre de Jefes de Estado y de Gobierno del Grupo de Río tiene lugar una vez al año, y ha sido celebrada ininterrumpidamente desde 1987.

26 José Antonio Sanahuja, "Un diálogo estructurado y plural. La dimensión institucional de las relaciones Unión Europea-América Latina”, Revista Nueva Sociedad, núm. 189, 2004, pp. 87-88.

${ }^{27}$ Levi, art. cit., p. 486. 
El medio que ha institucionalizado al más alto nivel el diálogo político entre la UE y AL es la celebración periódica de cumbres de jefes de Estado y de gobierno de las dos regiones para tratar una agenda previamente establecida. Las cumbres han supuesto aportes interesantes en las relaciones mutuas. Es verdad que la opción de celebrar Cumbres de este tipo entre las dos regiones respondió al momento histórico en el que se adoptó la decisión, puesto que "por entonces las relaciones internacionales estaban anegadas por la celebración de Cumbres de todo tipo. Por ello, si se quería otorgar trascendencia a las relaciones entre ALC y UE siempre pareció oportuno y necesario que tuvieran lugar este tipo de reuniones", tal como lo señala Díaz Barrado. Desde la primera cumbre entre la UE y ALC, celebrada en Río de Janeiro en junio de 1999, han tenido lugar ocho reuniones, primero AL-CUE y después UE-CELAC. ${ }^{28}$ Conviene tener presente que la última cumbre UE-CElAC que se tendría que haber celebrado en El Salvador en octubre de 2017 se pospuso sine die, por los desacuerdos entre los países latinoamericanos en torno a Venezuela. ${ }^{29}$ Las cumbres han delimitado el campo de actuación y los márgenes de maniobra que tienen los Estados de uno y otro lado del Atlántico. Pero, sobre todo, han señalado las orientaciones básicas y lineamientos que tienen que estar presentes en las relaciones birregionales. ${ }^{30}$ Para algunos analistas

${ }^{28}$ La Comunidad de Estados Latinoamericanos y Caribeños (CELAC) se creó en 2011. Es el único grupo regional que habla en nombre de toda la región de América Latina y el Caribe desde entonces. Se creó mediante la "Declaración de Caracas" y sustituyó al Grupo de Río, que databa de 1986, y a la efímera Cumbre de América Latina y el Caribe sobre Integración y Desarrollo (CALC). La CELAC reúne a 33 naciones soberanas en una comunidad intergubernamental con un bajo nivel de institucionalización y sin estructuras permanentes, como una secretaría permanente, y carece de mecanismos e instituciones para aplicar decisiones comunes. Sus decisiones son consensuadas y se adoptan durante las cumbres anuales.

${ }^{29}$ Ruano, art. cit., pp. 71-72.

30 Cástor Miguel Díaz Barrado, "América Latina-Caribe y Unión Europea: propuestas para una difícil articulación de la cooperación en la primera mitad del siglo xxı", Documento de Investigación 27/2018, Instituto Español de Estudios Estratégicos (IEEE), 2018, pp. 10-11. 
el mecanismo de las cumbres ha sufrido un cierto grado de agotamiento "por exceso de retórica y poco seguimiento en los resultados producto de los compromisos asumidos durante las Cumbres". ${ }^{31}$ Sin embargo, han permitido reunir en una misma mesa a todos los "responsables de adoptar decisiones" de las regiones para tratar temas de interés común, algo que no hubiera sido posible pensar en las décadas pasadas cuando se adolecía justamente de falta de interlocutores a nivel regional, a juicio de Levi. ${ }^{32}$ En cualquier caso, parece que las cumbres no han respondido plenamente a las expectativas que cabría esperar y, en algunos aspectos, se han convertido en un espacio idóneo para la retórica y, a lo sumo, para la proclamación de principios y determinación de áreas para la cooperación entre ambas regiones". ${ }^{33}$

Finalmente, cabe recalcar que, al margen de las cumbres se han desarrollado eventos empresariales y de la sociedad civil, en los que han participado actores que normalmente no tienen acceso a la toma de decisiones al más alto nivel, para expresar sus ideas favorables o contrarias sobre los temas que se discuten en esos foros. ${ }^{34}$

Los grandes temas de este diálogo político en los distintos niveles han sido la cohesión social, la integración regional, el respeto y la defensa de los derechos humanos, la gobernabilidad democrática, la reforma del Estado, la consolidación del Estado de derecho y sus instituciones, la lucha contra la corrupción, y la defensa del multilateralismo. ${ }^{35}$ No obstante, en términos principalmente sectoriales ha habido una significativa ampliación temática: drogas, cambio climático, migraciones, desarrollo sostenible, crisis económica, ciencia y

${ }^{31}$ Christian Freres, “¿De las declaraciones a la asociación birregional? Perspectivas de las cumbres entre la Unión Europea y América Latina y el Caribe”, Revista Nueva Sociedad, núm. 189, 2004, pp. 110-124. Freres et al., art. cit., p. 6.

32 Levi, art. cit., p. 489.

33 Díaz Barrado, art. cit., pp. 9-10.

${ }^{34}$ Levi, art. cit.

35 Alemany, art. cit., p. 46. 
tecnología, entre otros, con el fin de adaptar el diálogo a los temas más relevantes de la agenda global. En los últimos tiempos, el eje principal del diálogo birregional ha sido la cohesión social, en relación con la cual existen importantes diferencias entre los países participantes, especialmente en el caso latinoamericano. ${ }^{36}$

De acuerdo con Del Arenal, ${ }^{37}$ un balance esquemático de lo que han supuesto estos múltiples esquemas y foros de diálogo arrojaría los resultados que menciono a continuación. En primer lugar, la obsolescencia del diálogo uE-Grupo de Río, tanto por su limitación de agenda, como por su progresiva pérdida de peso político, visibilidad y representatividad.

En lo que se refiere a las Cumbres ALC-UE y UE-CELAC, del lado positivo, hay que destacar la visibilidad y ampliación de la agenda temática que han supuesto y su carácter movilizador en términos gubernamentales y de sociedades civiles, con la puesta en marcha de importantes programas de cooperación. Del lado negativo sobresale su excesiva retórica, que les ha impedido ser un foro realmente operativo, y el haberse transformado, en una medida importante, en foro de negociación de las agendas bilaterales de los países participantes, lo que debilita otros foros de diálogo, especialmente subregionales. Por otro lado, al integrar en ese diálogo a todos los países de ALC, con las divisiones, heterogeneidades y divergencia de posiciones e intereses que les caracterizan, se han minimizado los resultados del diálogo político.

A nivel de subregiones, el diálogo uE-América Central fue realmente fructífero en la década de los ochenta y principios de los noventa, si bien posteriormente entró en una fase de estancamiento, como consecuencia de las demandas centroamericanas no satisfechas de apertura de negociaciones para la firma de un Acuerdo de Asociación y sus reticencias ante la conclusión de un Acuerdo de "tercera generación" plus, en 2003, que no satisfacía sus aspiraciones. Esta situación se pro-

36 Arenal, 2010, art. cit., p. 35.

37 Ibid., pp. 36-40. 
longó hasta la Cumbre de Viena, en 2006, que abrió la puerta para el inicio de las negociaciones conducentes a la firma de un Acuerdo de Asociación UE-Centroamérica, firmado en 2013. Algo parecido puede decirse del diálogo UE-CAN, reforzado a partir de la conclusión del Acuerdo de "tercera generación” plus, en 2003, si bien en este caso la problemática interna de la CAN y la marcada división política existente en su seno ha impedido que este diálogo funcione adecuadamente, como se pone de manifiesto especialmente en las negociaciones comerciales para la conclusión de un acuerdo de asociación. Como se sabe, finalmente, no se ha logrado este acuerdo de asociación con la CAN, sino un acuerdo multipartes con Colombia, Perú y Ecuador. El diálogo uE-MERcosur, formalizado en 1995, a raíz de la conclusión del acuerdo marco de "cuarta generación" entre ambas partes, ha funcionado en términos generales, a pesar de que no ha permitido la conclusión de las negociaciones para la firma de un acuerdo de asociación, iniciadas precisamente a raíz de la celebración de la Cumbre de Río, en 1999, hasta el 28 de junio de 2019. La firma de este acuerdo, después de 20 años de negociaciones, sin duda puede marcar una nueva era en las relaciones entre ambos bloques.

Los diálogos bilaterales, con México y Chile, a partir de los acuerdos de asociación de 2000 y 2002, que suponen un considerable avance institucional a través del Consejo previsto en ambos acuerdos, y con Brasil, a partir del establecimiento de la asociación estratégica, en 2007, han sido los más positivos, aunque no siempre suficientemente aprovechados, poniendo de manifiesto que la vía bilateral no sólo es la preferida por los países latinoamericanos, sino la que permite, lógicamente, una más efectiva concertación ante la división y diferentes intereses en ALC.

Los diálogos interparlamentarios han permitido mantener los contactos y el intercambio de información entre los parlamentarios de ambas regiones, facilitando la puesta en marcha de determinados programas, aunque su incidencia en las relaciones entre la UE y ALC ha sido reducida. La crea- 
ción de Eurolat, a partir de la Cumbre de Viena, en 2006, ha permitido el reforzamiento de este diálogo.

Los diálogos con la sociedad civil, prácticamente inexistentes con anterioridad a la Cumbre de Guadalajara, en 2004, e indispensables para el progreso de las relaciones birregionales y la materialización efectiva de muchos de los programas de cooperación, han avanzado especialmente en el marco de los acuerdos de asociación (AA), si bien podría decirse que continúan siendo uno de los desafíos pendientes de ambas regiones.

Podría concluirse, en términos generales, que el carácter eminentemente normativo que caracteriza los foros de diálogo, los debilita desde el punto de vista de sus resultados prácticos.

\section{La cooperación}

El segundo pilar en el que se soporta la relación UE-ALC es la cooperación, modalidad de asistencia técnica ejecutada por la Comisión Europea, de conformidad con reglamentos adoptados por el Consejo y el Parlamento. Por ello, la discusión sobre el contenido de la misma no se da a través de las relaciones bilaterales, sino en el marco interno de la UE. ${ }^{38}$

${ }^{38}$ Hay que tener presente que, desde 2007, la ayuda financiera y técnica y cooperación económica de la uE para países en vía de desarrollo de Asia y ALC se rige por el Reglamento (CE) núm. 1905/2006 del Parlamento Europeo y del Consejo, de 18 de diciembre de 2006, por el que se establece un Instrumento de Financiación de la Cooperación al Desarrollo (ICD). Los objetivos y principios generales del ICD están formulados de acuerdo con el Tratado de Lisboa.

El ICD abarca cinco programas geográficos: ALc, Asia, Asia Central, Oriente Medio y Sudáfrica, y cinco programas temáticos: invertir en los ciudadanos, medio ambiente y gestión sostenible de los recursos naturales, entre ellos, la energía, agentes no estatales y autoridades locales en desarrollo, seguridad alimentaria, y migración y asilo. Establece asignaciones financieras para cada uno de estos programas e indica las que corresponden a cada región. Para ALc, la cantidad total en 2007-2013 fue de 2622 millones de euros (Comisión Europea, op. cit., p. 8.). Para el periodo 2014-2020, las subvenciones concedidas son de 3600 millones de euros. Véase European Union External Action, "Relaciones UE-CELAC", 2018. 
Conviene tener en cuenta que la política de cooperación para el desarrollo de la ue experimentó un proceso de cambio muy significativo durante toda la década de 2000, que afectó directamente a ALc. Ciertamente, lo que se denominó la "nueva arquitectura de la ayuda" -derivada de los objetivos y principios recogidos en los Objetivos de Desarrollo del Milenio (oDM), el Consenso de Monterrey, de 2002, la Declaración de Roma sobre Armonización, de 2003, la Declaración de París sobre Eficacia de la Ayuda, de 2005, entre otros- supuso una reforma administrativa así como una reorientación de la política de cooperación para el desarrollo, situando sus prioridades hacia los sectores sociales básicos y a los países más pobres, que según las clasificaciones del Banco Mundial y de Naciones Unidas incluyen tanto a los países menos adelantados (PMA), como los de renta baja (Low Income Countries, LIC). Ello supuso orientar la ayuda hacia África subsahariana y Asia oriental y meridional, en detrimento de los denominados "países de renta media" (PRM), entre los que precisamente se encontraban la totalidad de los países latinoamericanos y caribeños, salvo Haití. ${ }^{39}$ Por ello, la mayoría de los países latinoamericanos (y Bahamas en el Caribe) dejaron de beneficiarse de la cooperación para el desarrollo a través de programas geográficos bilaterales de la UE desde 2014, porque fueron clasificados como países de renta media-alta por la OCDE y, por lo tanto, ya no reunían los requisitos para recibir AOD de conformidad con las nuevas normas de la Unión. ${ }^{40}$

De este modo, la cooperación bilateral se suspendió para ocho países latinoamericanos de mayores ingresos, a saber, Argentina, Brasil, Chile, Costa Rica, México, Panamá, Uruguay y Venezuela en 2014. Venezuela y los países afectados por la crisis de Venezuela se benefician desde 2018 del apoyo humanitario y de emergencia. Para el periodo 2014-2020, el ICD

${ }^{39}$ Sanahuja, 2008, art. cit., p. 6; Del Arenal, 2010, art. cit., p. 40, y Malamud, 2010, art. cit., p. 20.

${ }^{40}$ Servicio Europeo de Acción Exterior, Comisión Europea, "Development Cooperation Instrument (DCI) 2014-2020: Multiannual Indicative Regional Programme for Latin America”, sEAE, Comisión Europea, 2015. 
asigna fondos a programas geográficos que cubren la cooperación de la uE con diez países latinoamericanos y caribeños que siguen pudiendo optar por la cooperación al desarrollo bilateral: Bolivia, Cuba, Paraguay y cuatro países centroamericanos (El Salvador, Guatemala, Honduras y Nicaragua), así como Colombia, Ecuador y Perú (en principio solo hasta finales de 2017), frente a los dieciocho que, durante el periodo 2007-2013, podían acogerse a la cooperación bilateral. ${ }^{41}$

No obstante, hay que señalar que la UE es el mayor donante multilateral de ayuda oficial al desarrollo (AOD) en ALC y el primer donante si se considera en su conjunto los fondos aportados por los Estados miembros y la Comisión Europea. Así, en relación a la distribución de los fondos de la AOD de la Comisión Europea por regiones, a nivel global, América Latina y el Caribe representaba 9.1\% del total de los fondos aportados al inicio de la década de 1990, y $7.5 \%$ en 2010-2011 (véanse gráficas 1 y 2).

Por otro lado, la desagregación de la AOD recibida por ALC durante los 21 años que van de 1990 a 2011 muestra a la Unión Europea en su conjunto como el principal donante, con $47 \%$ del total de la ayuda recibida. ${ }^{42}$ En 2012, la Unión Europea, representó $43 \%$ de toda la Ayuda Oficial al Desarrollo del mundo, y un $12 \%$ del total si se considera únicamente la AOD de las instituciones europeas. Respecto a los flujos provenientes de los Estados miembros, éstos se redujeron 3\% en relación con el inicio de la década de 1990, mientras que la ayuda de la Comisión Europea se expandió de 5\% a 12\% en América Latina. Para el bienio 2010-2011, el conjunto de la ayuda europea representa el $47 \%$ para la región, en comparación con el 43\% del bienio 1990-1991 ${ }^{43}$ (véanse gráficas 3 y 4).

${ }^{41}$ Müller, art. cit., pp. 53-54.

42 José E. Durán Lima et al., La cooperación entre América Latina y la Unión Europea: una asociación para el desarrollo, Santiago de Chile, CEPAL, 2013, p. 14.

43 Ibid., p. 14. 


\section{GRÁFICAS 1 Y 2}

Distribución de la ayuda oficial al desarrollo (AOD) de la uE por regiones receptoras, 1990-1991 y 2010-2011 (en porcentajes)
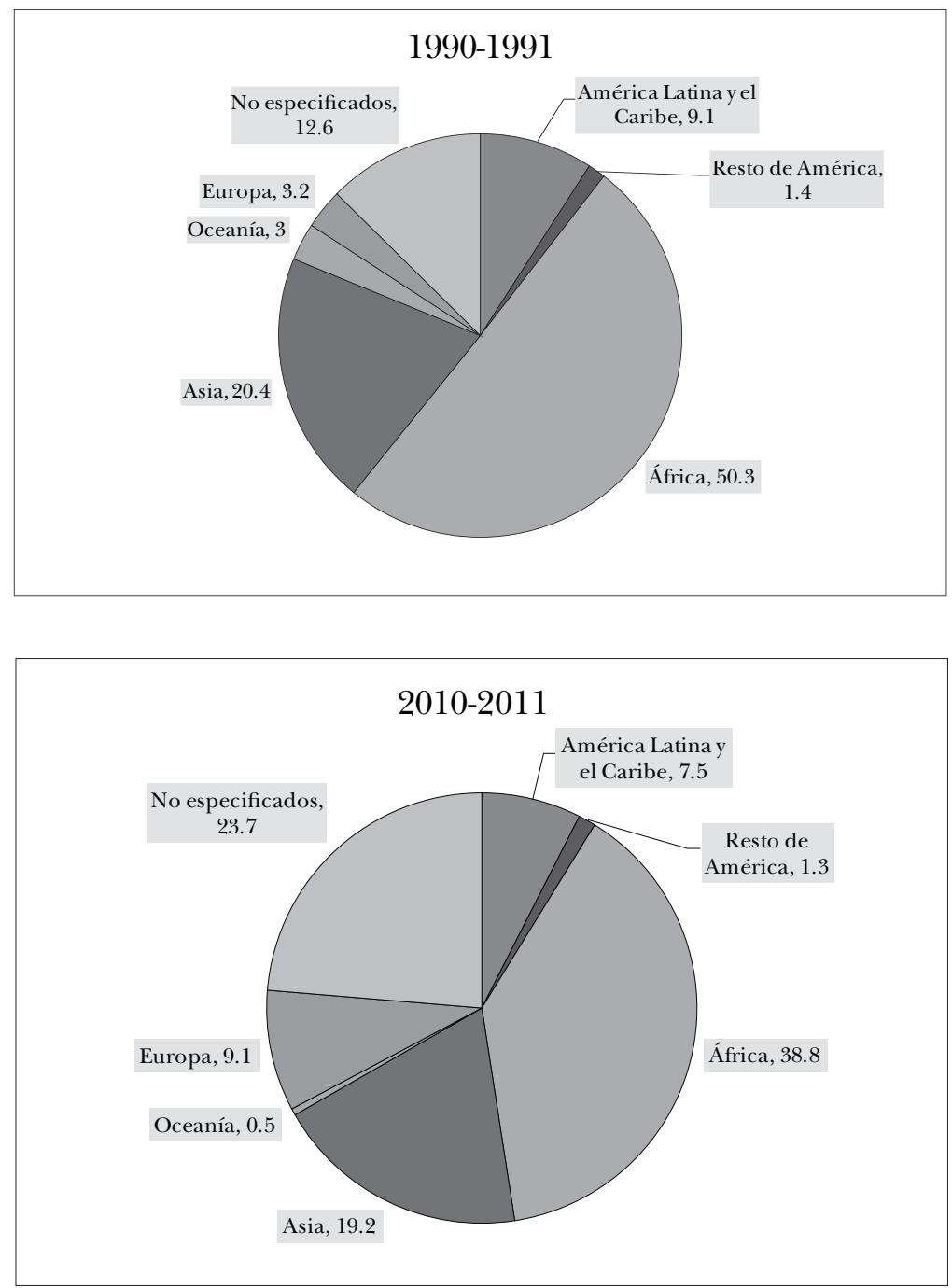

Fuente: Comisión Económica para América Latina y el Caribe (CEPAL), sobre la base de información de la oCDE. Durán et al., ibid., p. 15. 
GRÁFICAS 3 Y 4

Distribución de la AOD en América Latina y el Caribe por donante, 1990-1991 y 2010-2011 (en porcentajes)
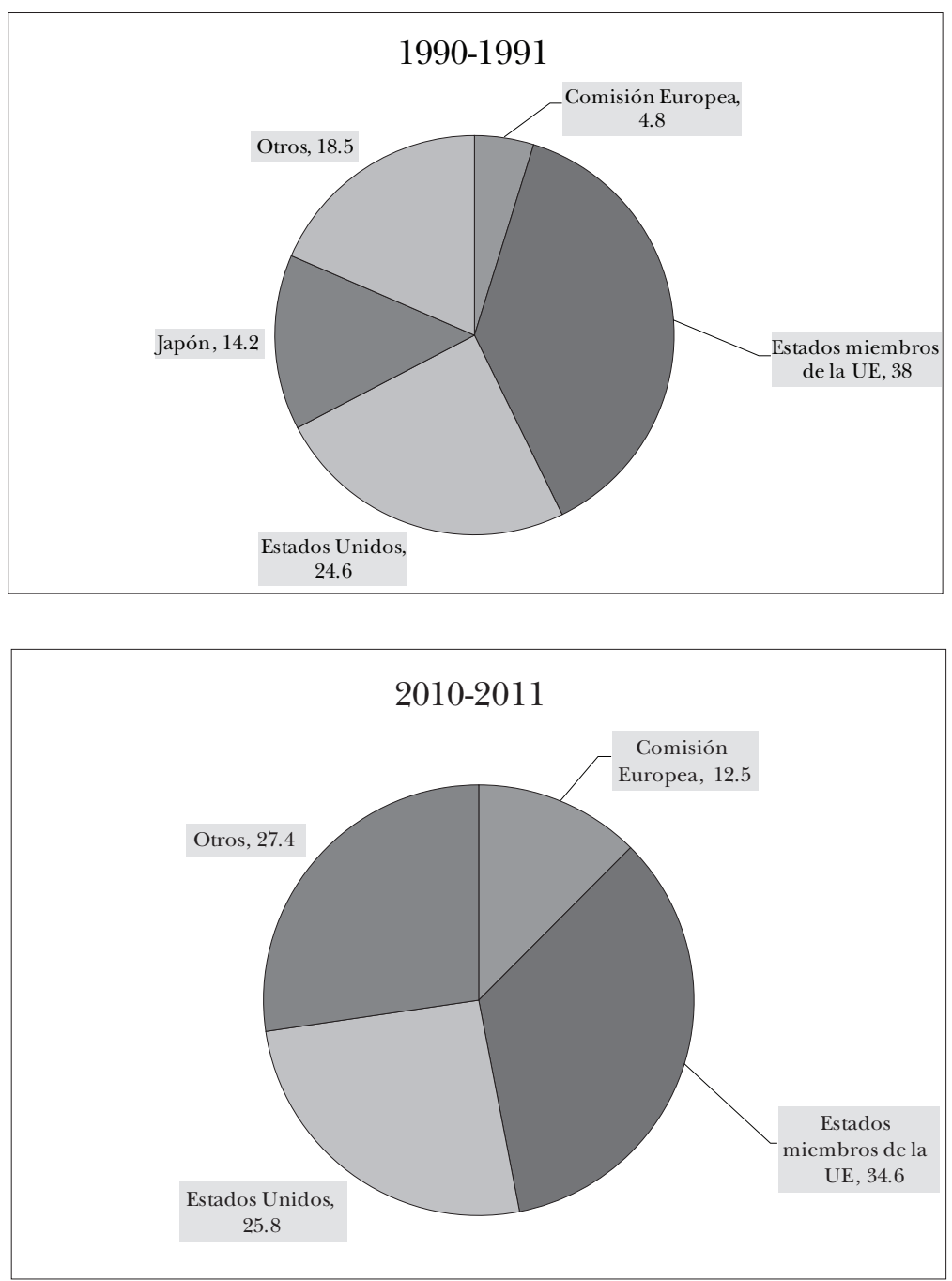

Fuente: Comisión Económica para América Latina y el Caribe (CEPAL), sobre la base de información de la ocDE. Durán et al., ibid., p. 15. 
Considerando la evolución de la AOD de los países de la UE y de aquella AOD originaria de las instituciones de la UE, se puede determinar que entre los trienios 1990-1992 y el 20092011, España y Francia aumentaron su participación relativa en el total de la AOD europea. Por su parte, Alemania, si bien disminuyó su participación en el periodo, se mantiene como uno de los principales donantes del grupo de los países de la UE. Las instituciones europeas pasaron al primer lugar de origen de la AOD de la UE. Otros países de relevancia son Holanda y Suecia, con participaciones destacadas ${ }^{44}$ (véase el cuadro 2).

\section{Cuadro 2}

Evolución de la AOD de los Estados miembros de la UE hacia América Latina, 1990-1992, 2000-2002 y 2009-2011 (en millones de dólares y tasas de crecimiento anual)

\begin{tabular}{|l|c|c|c|c|c|}
\hline \multirow{2}{*}{$\begin{array}{c}\text { Estados } \\
\text { miembros UE }\end{array}$} & \multicolumn{3}{|c|}{ Porcentaje del total } & \multicolumn{2}{c|}{ Crecimiento anual } \\
\cline { 2 - 6 } & $1990-1992$ & $2000-2002$ & $2009-2011$ & $1990-2000$ & $2001-2011$ \\
\hline Instituciones UE & 11 & 20 & 26 & 3 & 8 \\
España & 13 & 22 & 22 & 6 & -1 \\
Alemania & 23 & 17 & 17 & -5 & 11 \\
Francia & 11 & 6 & 14 & -6 & 24 \\
Holanda & 11 & 11 & 5 & -7 & -4 \\
Suecia & 5 & 6 & 3 & 8 & 2 \\
Bélgica & 2 & 2 & 2 & 0 & 10 \\
Dinamarca & 1 & 4 & 2 & 12 & 1 \\
Reino Unido & 3 & 8 & 2 & 8 & -2 \\
Italia & 17 & & 2 & -56 & 91 \\
Finlandia & 1 & 1 & 1 & -7 & 17 \\
Luxemburgo & 0 & 1 & 1 & 23 & 8 \\
Austria & 1 & 2 & 1 & 4 & -11 \\
Irlanda & 187 & 178 & 187 & & 10 \\
\hline Total & & & & 38 & \\
\hline
\end{tabular}

Fuente: Comisión Económica para América Latina y el Caribe (CEPAL), sobre la base de información de la ocDE. Durán et al., ibid., p. 18.

44 Ibid., p. 18. 
En relación con los sectores prioritarios de la programación regional y subregional de la AOD de la UE, tocantes a la programación 2007-2013, éstos han correspondido, en términos generales, a los que están establecidos para ALc por el Instrumento para la Cooperación al Desarrollo (ICD) a través del Documento de Estrategia Regional (DER) para la programación regional y en los tres Documentos Estratégicos Regionales para las tres programaciones subregionales (véase el cuadro 3 ).

Desde 2014, los sucesivos planes de acción anuales de cooperación entre ALC y la UE se han focalizado en las siguientes acciones: políticas de drogas, incluido el Caribe (COPOLAD II); en seguridad-cumplimiento de la ley, judicial y penitenciario (el PACCTO); sobre gestión de fronteras (Eurofron); sobre cohesión social, género y buen gobierno (Eurosocial+); sobre crecimiento inclusivo para la cohesión social (AL-INVEST 5.0); sobre conectividad digital (BELLA-T); en inversión con el mecanismo de inversión de América Latina (LAIF); sobre cambio climático y protección del medio ambiente (Euroclima + ); sobre cooperación triangular (Adelante); sobre enfoques innovadores para la cooperación (Desarrollo en instalaciones de transición). Además de estas acciones regionales, el programa ERASMUS +, financiado por DCI, LO implementa el departamento de educación y cultura de la Comisión Europea.

En cuanto a los fondos ejecutados durante el periodo 2007-2013 con cargo al ICD, cabe apuntar que han alcanzado los 2920 millones de euros, sobre un total de 2622 millones comprometidos, según se ha indicado anteriormente. El principal sector de concentración de los fondos bilaterales ejecutados a nivel regional ha sido Desarrollo social y cohesión social, con 1221 millones de euros, 56\% del total de fondos bilaterales; le ha seguido el sector Desarrollo económico y comercio, con 365.7 millones de euros ejecutados, equivalentes a $17 \%$ de la programación bilateral. En tercer lugar, se ha ubicado el sector Medio ambiente, cambio climático, agua y desastres naturales, con 288 millones 


\section{Cuadro 3 \\ Unión Europea: resumen de prioridades globales, regionales, subregionales de la AOD de la UE en la programación 2007-2013}

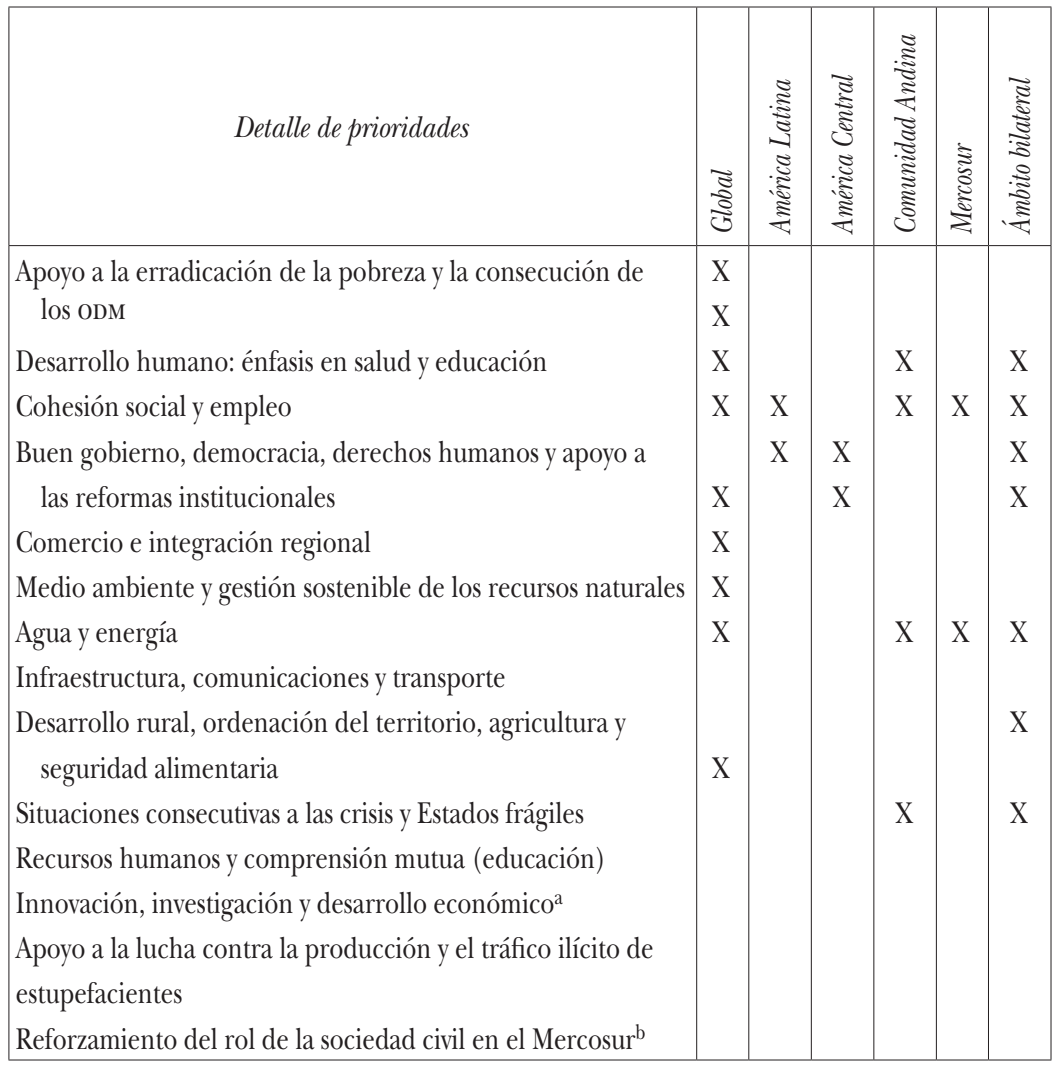

Fuente: Comisión Económica para América Latina y el Caribe (CEPAL) con base en el Reglamento (CE) N 1905/2006 del Parlamento Europeo y del Consejo de 18 de diciembre de 2006 (ICD), el Documento de Estrategia Regional, los tres Documentos de Estrategia Subregional y los 18 Documentos de Estrategia País 2007-2010 de la Comisión Europea; Durán et al., ibid., p. 39.

a Prioridad de carácter bilateral.

b Prioridad de carácter subregional y bilateral. 
de euros, igual a 13\%, seguido por el sector Democracia, derechos humanos y buen gobierno, con 217.5 millones de euros ejecutados, $10 \%$ del total de la programación bilateral $y$, finalmente, en quinto lugar ha estado el sector Recursos humanos y comprensión mutua, con 52 millones de euros ejecutados, un $2 \%$ de los fondos. Por otro lado, cabe apuntar que de los fondos comprometidos para la programación 2007-2013, Centroamérica en su conjunto ha representado el $41 \%$ del total de los fondos comprometidos a nivel bilateral; la Comunidad Andina, 36\%; el Mercosur un $15.5 \%$ y en los países no agrupados, incluido Cuba, $7.3 \%$. Del total de los fondos bilaterales comprometidos, más de dos tercios $(80 \%)$ han correspondido a nueve países: el Estado Plurinacional de Bolivia, Honduras y Nicaragua, con más de 200 millones de euros comprometidos, y Colombia, Guatemala, Ecuador, Perú, Paraguay y El Salvador con más de 100 millones de euros comprometidos. Pero, así como la AOD de la Unión Europea sigue siendo significativa para muchos de los países de la región, para otros estos fondos de la AOD han ido disminuyendo progresivamente y se han vuelto menos relevantes para su desarrollo, en la medida que estos fondos, debido a los distintos acuerdos y consensos alcanzados por la comunidad internacional, están enfocados principalmente hacia el cumplimiento de los oDm y la lucha contra la pobreza. De esta forma, el $20 \%$ restante de la AOD comprometida en la región por la Comisión Europea, a nivel bilateral, ha correspondido a nueve países: Argentina, Brasil, México, Chile, la Republica Bolivariana de Venezuela, Panamá, Costa Rica y Cuba, en este orden. ${ }^{45}$

A partir de 2014 y hasta 2018, último año de los datos ofrecidos por la OCDE, la evolución de la AOD permite presentar la siguiente información (véase el cuadro 4).

${ }^{45}$ Durán et al., art. cit., pp. 55-61. 
Cuadro 4

Evolución de la AOD de la UE por regiones receptoras, 2014-2018 (en porcentajes sobre el total)

\begin{tabular}{|l|r|r|r|r|r|r|}
\hline \multicolumn{1}{|c|}{ Región } & \multicolumn{1}{c|}{2013} & 2014 & 2015 & 2016 & 2017 & 2018 \\
\hline América Latina y el Caribe & 6.22 & 4.33 & 7.72 & 6.64 & 5.35 & 8.08 \\
África & 37.92 & 41.11 & 38.21 & 37.59 & 39.40 & 39.82 \\
Asia & 17.99 & 17.24 & 22.07 & 21.84 & 23.15 & 24.86 \\
Oceanía & 0.60 & 0.58 & 0.82 & 0.42 & 0.64 & 0.82 \\
Europa & 30.79 & 29.76 & 24.43 & 26.68 & 21.89 & 15.33 \\
No especificados & 6.47 & 6.98 & 6.75 & 6.83 & 9.56 & 11.10 \\
\hline
\end{tabular}

Fuente: elaboración propia sobre la base de información de la ocDE, https://stats.oecd.org

Como lo muestran estos datos, la AOD recibida por ALC de la UE ha disminuido con respecto a periodos anteriores a favor de otras regiones, como Asia, Europa y África.

No obstante, las cifras de la OCDE indican que la AOD aportada por la UE y sus Estados miembros a ALC han consolidado su posición como principales donantes de ayuda a ALC (véase cuadro 5).

Los datos ponen en evidencia que son Alemania y Francia los Estados miembros de la ue que más contribuyen a la AOD dirigida a ALC. España, con presupuestos más reducidos, ha seguido priorizando ALC como la principal área receptora de su AOD. Llama la atención la cifra de 2016. Este sustancial aumento de la cifra de AOD estuvo motivada por la firma de un acuerdo de alivio de deuda y un programa de conversión que España firmó con Cuba en ese año.

Con base en todo lo mencionado, el balance que puede hacerse sobre la evolución de este pilar de la cooperación, siguiendo a Del Arenal, ${ }^{46}$ podría sintetizarse del siguiente modo. En términos generales, hay que reconocer que, en materia de cooperación, la uE ha realizado un importante esfuerzo de

${ }^{46}$ Arenal, 2010, art. cit., pp. 42-46. 
adaptación a las demandas derivadas de la nueva arquitectura de la ayuda y a las propias demandas latinoamericanas. Con todo, ha continuado destacando la falta de complementariedad y coordinación entre los distintos programas de cooperación, regionales, subregionales y bilaterales, en que los planteamientos sectoriales tienden a ser dominantes, respondiendo a dinámicas y prioridades que pueden incluso llegar a ser contradictorias, así como su excesiva rigidez para adaptarse a las circunstancias cambiantes y heterogéneas que presenta la región.

\section{Cuadro 5}

Evolución de la AOD en América Latina y el Caribe por donante, 2014-2018 (en porcentajes sobre el total)

\begin{tabular}{|l|r|r|r|r|r|r|}
\hline \multicolumn{1}{|c|}{ Región } & 2013 & 2014 & 2015 & 2016 & 2017 & 2018 \\
\hline Instituciones de la UE & $\mathbf{6 . 2 2}$ & 4.33 & $\mathbf{7 . 7 2}$ & $\mathbf{6 . 6 4}$ & $\mathbf{5 . 3 5}$ & $\mathbf{8 . 0 8}$ \\
Estados miembros de la UE & $\mathbf{2 8 . 7 0}$ & $\mathbf{3 4 . 5 2}$ & $\mathbf{2 8 . 9 1}$ & $\mathbf{4 7 . 0 2}$ & $\mathbf{3 1 . 9 4}$ & $\mathbf{3 3 . 6 9}$ \\
España & 2.27 & 0.48 & 1.13 & 19.81 & 2.24 & 2.77 \\
Alemania & 12.59 & 17.77 & 11.26 & 13.64 & 12.07 & 13.33 \\
Francia & 7.38 & 10.65 & 11.12 & 7.71 & 7.66 & 9.81 \\
Países Bajos & 0.74 & 0.41 & 0.25 & 0.12 & 0.08 & 0.29 \\
Suecia & 1.22 & 1.25 & 0.98 & 1.01 & 1.34 & 1.23 \\
Bélgica & 0.83 & 0.94 & 0.68 & 0.71 & 0.77 & 0.68 \\
Dinamarca & 0.01 & 0.34 & 0.34 & 0.28 & 0.61 & 0.30 \\
Reino Unido & 2.16 & 1.08 & 2.04 & 2.73 & 5.13 & 4.50 \\
Italia & 0.34 & 0.45 & 0.38 & 0.31 & 1.24 & 0.04 \\
Finlandia & 0.47 & 0.46 & 0.25 & 0.12 & 0.09 & 0.05 \\
Luxemburgo & 0.33 & 0.29 & 0.21 & 0.22 & 0.27 & 0.27 \\
Austria & 0.25 & 0.28 & 0.18 & 0.26 & 0.33 & 0.32 \\
Irlanda & 0.11 & 0.12 & 0.09 & 0.10 & 0.11 & 0.10 \\
Estados Unidos & $\mathbf{1 9 . 7 6}$ & $\mathbf{1 9 . 9 8}$ & $\mathbf{1 9 . 4 5}$ & $\mathbf{1 6 . 3 9}$ & $\mathbf{2 3 . 6 6}$ & $\mathbf{2 0 . 2 9}$ \\
Otros & $\mathbf{4 5 . 3 2}$ & $\mathbf{4 1 . 1 7}$ & $\mathbf{4 3 . 9 2}$ & $\mathbf{3 6 . 5 9}$ & $\mathbf{3 9 . 0 5}$ & $\mathbf{3 7 . 9 4}$ \\
\hline
\end{tabular}

Fuente: elaboración propia sobre la base de información de la ocDE, https://stats.oecd.org 
Los programas de cooperación subregional, con Mercosur, la CAN y Centroamérica, al contar con interlocutores directos, a pesar de que el compromiso financiero ha sido reducido, han tenido resultados más positivos desde el punto de vista de la integración y el regionalismo.

El proceso de definición de la política de cooperación de la UE, de carácter unilateral, de acuerdo con las normas comunitarias, no se ha ajustado adecuadamente a los marcos multilaterales, regionales y subregionales, en los que se desenvuelve la cooperación con ALc. Tampoco se ha ajustado debidamente al modelo de relación, más horizontal, de los acuerdos de asociación. Todo ello ha acentuado el carácter asimétrico que, en sí misma, como consecuencia de la falta de cohesión intragrupo en el ámbito latinoamericano, ha tenido la cooperación birregional, lo que la ha debilitado ante los países latinoamericanos, que hubieran preferido una cooperación planteada en términos bilaterales, como lo apunta Del Arenal. ${ }^{47}$

En todo caso, tal como se mencionó anteriormente, los programas de cooperación con AL no se han aproximado en recursos con los ejecutados en otras regiones, como el PHARE para países de Europa Central y del Este, TACIs para las antiguas repúblicas soviéticas, MEDA para países terceros mediterráneos, o el Fondo Europeo de Desarrollo (FED) para los países de África, Caribe y Pacífico. ${ }^{48}$

En suma, podría concluirse que la UE pareciera haber puesto especial interés en promover la cooperación al desarrollo como un instrumento junto con los acuerdos marco o de asociación. Sin embargo, actualmente, la realidad de los países que integran la Asociación Estratégica entre la UE y la actual CELAC es bastante diferente a la imaginada al inicio de la década de $1990 .^{49}$

47 Ibid, p. 44.

48 Tremolada, art. cit., p. 203.

${ }^{49}$ Durán et al., art. cit., p. 12. 


\section{El comercio}

Constituye la tercera y última columna que sostiene la relación UE-ALC. Como se sabe, en la II Cumbre UE-ALC, celebrada en Madrid en 2002, el foco de atención estuvo especialmente en los temas comerciales. La IV Cumbre UE-ALC realizada en 2006 en Viena, volvió a poner el acento en el tema comercial, pero manteniendo la cohesión social como una prioridad en la agenda birregional, incorporando el desarrollo sostenible y las migraciones como nuevas prioridades. En la Cumbre de Lima, en 2008, se planteó el objetivo de avanzar decididamente en lo que respecta a las negociaciones comerciales entre la UE y los diferentes agrupamientos de integración subregional de ALC. Sin embargo, una serie de factores -entre los cuales cabe destacar el impacto desfavorable sobre los intercambios y sobre la disposición negociadora de las partes del agravamiento de la crisis económica internacional a partir de septiembre de 2008, así como los problemas internos en Mercosur y la CAN- han entorpecido este proceso en la medida en que han afectado negativamente las relaciones económicas ALC-UE. ${ }^{50}$

Los flujos financieros, en particular las corrientes de inversión extranjera directa (IED), han constituido el ámbito más dinámico de las relaciones económicas interregionales. La IED, donde la IED de origen europeo hacia América Latina y el Caribe ha adquirido una importancia creciente, ha pasado por diferentes etapas desde comienzos de los años noventa.

La IED hacia ALC registró un gran auge durante los años noventa. En esta década, los contextos económicos de América Latina y de Europa se complementaron para permitir una notable alza de los flujos de IED. En América Latina se implementaron reformas estructurales para acelerar la inserción internacional, eliminando muchas restricciones al capital extranjero en los sectores de los hidrocarburos, la minería

${ }^{50}$ Ibid., p. 114. 
y los servicios, hasta entonces reservados a las empresas estatales. Las entradas de IED tuvieron un auge sin precedentes y muchas empresas europeas ingresaron a sectores hasta entonces cerrados a su actividad, mediante los procesos de privatización. Mientras tanto, en Europa, la implementación del mercado único presionó a las empresas a crecer y adquirir el tamaño necesario para competir en el mercado comunitario. Muchas empresas optaron por el crecimiento exterior mediante fusiones y adquisiciones como respuesta a este desafío, y buena parte de ellas aprovecharon la oportunidad que se les brindaba en América Latina. ${ }^{51}$

En este marco, los flujos provenientes de la UE superaron a los de Estados Unidos y pasaron a ser mayoritarios en la fase de auge de la segunda mitad de esa década. Este auge fue impulsado sobre todo por la expansión de la inversión de origen español. En efecto, en los años de 1990, España se transformó en el principal inversionista del viejo continente en ALC -seguido de Holanda y Francia-, con montos que representaron casi la mitad de los flujos totales de IED de origen europeo. La ola inversionista de España -que se reforzó también con la fuerte implantación de sus principales bancos en ALC- hizo que las firmas de este país alcanzaran una presencia internacional que antes era prácticamente inexistente, en particular en los sectores bancario, energético y de telecomunicaciones. Esa fase de auge, que alcanzó su punto máximo en 1999, fue seguida por una etapa de reflujo que se prolongó hasta 2003. A partir de 2004, se produjo un nuevo auge de la IED recibida por ALC, asociado, principalmente, al interés de los inversores internacionales por los recursos naturales con que dispone ALC en un contexto de alza de los precios de las materias primas. En ese nuevo marco, la IED de origen europeo presentó algunas características diferentes a la década anterior. En efecto, su espectacular auge en los años

${ }^{51}$ Comisión Económica para América Latina y el Caribe, CEPAL, $L a$ inversión extranjera directa en América Latina y el Caribe 2018, Santiago de Chile, 2018a, p. 174. 
noventa se debió en parte a factores de imposible repetición, como el proceso de privatizaciones que se desarrolló en numerosos países de la región latinoamericana y caribeña. En este periodo, ALc se constituyó la principal zona de implantación en los países y regiones emergentes y en desarrollo. En cambio, en la fase de auge 2004-2008, las inversiones europeas en Asia han superado las efectuadas en ALC. ${ }^{52}$

Tras la crisis financiera de 2008 y 2009, cuando las economías de ALC crecieron a ritmos elevados mientras que la mayoría de los países de Europa se vieron sumidos en una recesión, algunas transnacionales europeas, particularmente de España y Portugal, resultaron fuertemente afectadas por el desempeño de sus economías y tuvieron que reducir su ritmo de inversión regional. Si bien algunas de estas empresas se vieron forzadas a vender algunas filiales en la región, por lo general se trató solamente de activos periféricos, y ninguna empresa europea importante abandonó sus inversiones en América Latina como consecuencia de la crisis. Al contrario, las filiales en América Latina pasaron a ser las más rentables para muchas empresas europeas, lo que consolidó su importancia dentro del grupo y reivindicó la estrategia de inversión iniciada en la década de 1990. Durante la última década, han vuelto a surgir nuevas oportunidades en América Latina y muchas empresas europeas han sabido aprovecharlas para diversificar sus fuentes de ingreso y, en ocasiones, hacer frente a mercados internos estancados o en recesión. Por otra parte, Europa presenta características culturales, sociales y económicas que son especialmente atractivas para el actual proceso de desarrollo de ALC. ${ }^{53}$

En 2016, un 53\% de la IED que ingresó a la región se registró como proveniente desde países europeos. En general, los inversionistas europeos son más importantes en América del

${ }^{52}$ Sistema Económico Latinoamericano y del Caribe, sela, "Las relaciones económicas recientes de América Latina y el Caribe con la Unión Europea en vísperas de la Cumbre de Madrid", SP/RR-REALCUE-VICBM/DT núm. 2-10. Caracas, Venezuela, 2010, pp. 15-17.

${ }^{53}$ CEPAL, 2018a, op. cit., p. 174. 
Sur, en tanto que en México, Centroamérica y el Caribe prevalecen las empresas de Estados Unidos. Mientras que en Brasil la IED registrada como europea representa el $71 \%$ del total, en México alcanza el 32\% y en Centroamérica y la República Dominicana, en conjunto, sólo llega al 12\%. De todos modos, hay que considerar con cuidado los datos de IED desagregados por país de origen, debido a la práctica de las empresas de canalizar sus inversiones a través de terceros países, que son los que quedan registrados por las autoridades. Esto es especialmente claro en el caso de los Países Bajos, que figura en 2016 como el país europeo con más IED en la región: el 12\% del total. $\mathrm{Al}$ margen de lo anterior, los datos ponen de relieve la gran importancia de la UE como fuente de IED en la región y su especial foco en América del Sur. Cabe apuntar que, según la CEPAL, son tres los sectores en los que se ha concentrado la mayoría de la IED de la Unión Europea en América Latina, las energías renovables, las telecomunicaciones y el sector automotor. ${ }^{54}$

En lo que respecta al comercio birregional, como señala el ya citado informe del SELA, en las décadas de los años de 1990 y 2000, "éste ha sido poco dinámico, fuertemente concentrado y asimétrico". ${ }^{55}$ De forma resumida, puede decirse que entre 1993 y 1998 el comercio interregional se incrementó de forma sostenida, en especial las importaciones latinoamericanas de productos europeos, que crecieron a un ritmo mayor a las exportaciones latinoamericanas a la UE. Las crisis económicas de algunos países latinoamericanos afectaron los intercambios y entre 2000 y 2002 se vivió una fase de estancamiento. Entre 2003 y 2008 el comercio birregional volvió a crecer en ambas direcciones, gracias a la fase de crecimiento sostenido de las economías latinoamericanas y a la revalorización de las materias primas y alimentos exportados por AL. Entre 2003 y 2008 las exportaciones latinoamericanas a la UE crecieron $72 \%$, y las importaciones, $68 \%$. El mencionado in-

${ }^{54}$ Ibid, pp. 175-179.

${ }^{55}$ SELA, op. cit., p. 18. 
cremento de precios de las materias primas latinoamericanas condujo a la región a tener un saldo positivo en sus intercambios con Europa, aunque la crisis de 2008 se hizo sentir duramente a partir de la segunda mitad del año. ${ }^{56}$

Ciertamente, tras la crisis internacional del segundo semestre de 2008, la fase de crecimiento de los intercambios birregionales se interrumpió dando lugar a una brusca caída a fines de 2008-inicios de 2009, tras la cual los flujos comerciales se estabilizaron en un nivel más bajo. De este modo, en 2009, las importaciones provenientes de la UE acusaron una disminución de $35 \%$ en ritmo anual -contra una expansión de $10 \%$ en el año anterior-mientras que las exportaciones de ALC hacia la ue sufrieron una contracción de $27 \%$, contra un aumento de $19 \%$ en $2008 .{ }^{57}$

En efecto, tal como lo indica la CEPAL, el bajo crecimiento que afectó a buena parte de la UE desde la irrupción de la crisis internacional de 2008 se tradujo en un menor dinamismo del comercio intracomunitario. La participación de éste en las exportaciones totales de bienes de la uE cayó casi cinco puntos porcentuales entre 2008 y 2016, situándose en $62 \%$. En este contexto, han ganado participación Estados Unidos y China. En 2016, si se excluye el comercio intracomunitario, América Latina y el Caribe fue el destino del 6\% de las exportaciones de bienes de la UE al resto del mundo, y el origen del $5.3 \%$ de sus importaciones. ${ }^{58}$

Debe resaltarse la evolución que ha registrado el intercambio comercial de la región latinoamericana con China durante el presente siglo. Entre 2000 y 2017, la participación de este país en el comercio regional se multiplicó por nueve (desde una base muy reducida), pasando de $1 \%$ a $10 \%$ en el caso de las exportaciones, y de $2 \%$ a $18 \%$ en las importacio-

${ }^{56}$ Malamud, art. cit., p. 19.

${ }^{57}$ SELA, op. cit., p. 19.

${ }^{58}$ Comisión Económica para América Latina y el Caribe (CEPAL), La Unión Europea y América Latina y el Caribe: estrategias convergentes y sostenibles ante la coyuntura global, LC/TS.2018/56/Rev.1, Santiago de Chile, 2018b, p. 85 . 
nes. De este modo, en 2014 China desplazó a la ue como el segundo socio comercial de la región, detrás de Estados Unidos. En 2017, China representó el 14\% del comercio exterior regional (considerando exportaciones e importaciones), mientras el peso de la ue fue del $12 \%$. Si bien esta última continúa siendo el segundo mercado para las exportaciones de la región, ya en 2010 fue desplazada por China como el segundo origen de sus importaciones. Para los productores de la UE, la competencia china en la región ha sido especialmente marcada en el sector de la electrónica. ${ }^{59}$

Más allá de las diferentes etapas que la evolución del comercio birregional ha experimentado en estas ya casi cuatro décadas, sus rasgos básicos no se han modificado de una manera sustancial. Así, el comercio birregional sigue lastrado por una fuerte concentración, que es creciente, en los países que dominan los intercambios: Alemania, Francia, Gran Bretaña, Italia y España, del lado europeo, y Brasil, México, Argentina, Chile y Colombia del lado latinoamericano. Por otra parte, el bajo dinamismo relativo ha continuado siendo una de las notas características de los intercambios entre la UE y ALC, creciendo menos en ambas regiones que con otras zonas del mundo. Realmente, como se ha comentado ya, la participación europea en el comercio latinoamericano ha tenido una tendencia decreciente. El retroceso europeo se ha producido como consecuencia del aumento del asiático en el comercio latinoamericano, si bien, la UE -de forma agregada- se mantiene como el segundo socio comercial de ALC, tal como se ha indicado en párrafos anteriores. Por último, el comercio UE-ALC sigue caracterizándose por su gran asimetría en lo que respecta al tipo de bienes exportados por cada región. Mientras las importaciones latinoamericanas de productos europeos se centran básicamente en artículos industriales (cerca de 85\%), las exportaciones giran en torno a los productos primarios (un 40\%), una proporción mayor que la de otras regiones del mundo. Al mismo tiempo, la es-

${ }^{59}$ Ibid., p. 81. 
pecialización primaria en los intercambios con Europa es más marcada en el caso del MCCA, de la CAN y en menor medida de la Caricom, ya que en estos casos la proporción -en las ventas totales de estos agrupamientos subregionales hacia la UE- de las exportaciones de productos básicos es extremadamente elevada y superior al promedio regional. ${ }^{60}$

Conviene señalar, por otro lado, que la uE dispone de la mayor red mundial de acuerdos comerciales con América Latina y el Caribe. La uE tiene firmado algún tipo de acuerdo con todos los países latinoamericanos, salvo Bolivia y Venezuela, por lo que es el socio extrarregional que dispone de una mayor red de pactos de este tipo en la región. Le siguen Estados Unidos y sus acuerdos vigentes con 11 países. A diferencia de otros socios, la UE ha privilegiado las negociaciones de "bloque a bloque" con los principales mecanismos subregionales de integración de la región ${ }^{61}$ (véase cuadro 6).

\section{Cuadro 6}

Unión Europea: acuerdos comerciales con agrupaciones y países de ALC

\begin{tabular}{|c|c|c|}
\hline & Año de firma & Año de entrada en vigor \\
\hline \multicolumn{3}{|c|}{ Agrupaciones } \\
\hline Cariforum $^{\mathrm{a}}$ & 2008 & 2009 \\
\hline Centroamérica & 2012 & 2013 \\
\hline Países andinos ${ }^{b}$ & 2012 & 2013 \\
\hline \multicolumn{3}{|l|}{ Países } \\
\hline Chile & 2002 & 2003 \\
\hline México & 1997 & 2000 \\
\hline Mercosur & 2019 & $\begin{array}{l}\text { En fase de tramitación en el Parlamento } \\
\text { Europeo y los Parlamentos de Mercosur }\end{array}$ \\
\hline
\end{tabular}

Fuente: Comisión Económica para América Latina y el Caribe (CEPAL), sobre la base de información oficial, CEPAL, 2018, p. 92.

a Incluye a 14 países miembros de la Comunidad del Caribe (Caricom) y la República Dominicana.

b Colombia, Ecuador y Perú.

60 SELA, op. cit., pp. 19-22 y Malamud, art. cit., pp. 19-20.

61 CEPAL, 2018b, op. cit., p. 92. 
En suma, aunque prácticamente toda ALC, excepto Cuba, tiene institucionalizadas sus relaciones comerciales con la UE, la situación dista mucho de ser homogénea. Finalmente, tal como apunta Del Arenal, debe tenerse en cuenta que "las negociaciones para la conclusión de Acuerdos de Asociación no siempre han respondido al principio del apoyo a la integración, actuando en ocasiones en sentido contrario al mismo y debilitando con ello los mecanismos de integración latinoamericanos. Este hecho ha sido especialmente llamativo en el caso de la CAN, pero también en relación a Mercosur, como consecuencia del estancamiento de las negociaciones durante diez años. A reforzar este hecho se ha sumado la conclusión de Acuerdos de Asociación bilaterales con México y Chile, acuerdos sobre los que se está negociando actualmente para modernizarlos. El problema de fondo que subyace en esta cuestión es un problema de "coherencia de políticas”. A juicio de este autor, "continúa siendo un reto abierto la relación entre los acuerdos de asociación, especialmente en su dimensión comercial, y la apuesta por la cohesión social". ${ }^{62}$

\section{Conclusiones}

Del contenido de los apartados anteriores, pueden derivarse algunas ideas concluyentes. En primer lugar, cabe destacar que en muchas de las fuentes consultadas, tanto en documentos oficiales como trabajos académicos, se refleja la idea de que las relaciones entre la UE y ALC son especiales por el hecho de compartir una serie de valores civilizatorios, culturales e históricos. Las relaciones entre ALC y los países de la UE han sido tradicionalmente fuertes, se dice. Los lazos culturales y económicos que han unido históricamente ambas regiones se han transformado paulatinamente y han abierto múltiples espacios para la cooperación y el desarrollo.

${ }^{62}$ Del Arenal, 2010, art. cit., pp. 49-50. 
Se han constatado dos posturas extremas en cuanto a las relaciones entre la UE y ALC, que van desde el excesivo optimismo al excesivo pesimismo. Mientras la primera insiste en el gran potencial existente entre ambas regiones debido a que comparten valores comunes, lo que ha llevado a avanzar considerablemente en el proceso de construcción de una alianza estratégica, la segunda apunta a que, pese a algunos temas en común, las diferencias regionales son de tal calado que es imposible avanzar más allá de algunos compromisos coyunturales.

Podría decirse que ALC no es una región prioritaria en las relaciones exteriores de la UE. Este hecho debe ser el punto de partida al hacer un balance de éstas para no desvirtuar el análisis. Igualmente, algunos autores siguen pensando que los Estados latinoamericanos tienen otras prioridades en su política exterior. Se llega a plantear incluso que "no se evidencia ni estrategias ni prioridades en la política exterior de la Unión Europea hacia América Latina, por el contrario, está marcada por la inercia y es reactiva y coyuntural". ${ }^{63}$

Un aspecto de relevancia es el papel de España y de Portugal en el vínculo birregional, por sus poderosas relaciones histórico-culturales con ALC que ha operado, a veces, como gozne, bisagra y portavoz de las aspiraciones e intereses de ambas regiones ante su contraparte.

Repiten como mantras, sobre todo los expertos americanistas, los diagnósticos sobre "asimetrías", "fragmentación" y "heterogeneidad" existentes desde cualquier perspectiva que se analicen las relaciones UE-ALC.

Algunos datos ayudan a entender estas asimetrías a nivel institucional y económico entre las dos regiones. Mientras que la uE es una organización basada en tratados con importantes características y competencias supranacionales derivadas de la delegación de poderes de sus Estados miembros, la CELAC -creada en 2011 como único grupo regional que habla en nombre de toda la región de ALC, tal como se ha referido

63 Tremolada, art. cit., p. 208. 
anteriormente- es un foro informal, privado de estructura jurídica, sede, competencias y presupuesto. Por lo tanto, la asociación entre la UE y la CELAC puede definirse como "una relación interregional híbrida entre una organización muy institucionalizada y un bloque regional con escasa institucionalización o estructuras permanentes". Al mismo tiempo, existen similitudes entre la UE y la CELAC en cuanto al número de países en cada grupo regional (28 en el caso de la UE y 33 en el de la CELAC) y el tamaño de su población total; aproximadamente, 510 millones de habitantes en la UE y unos 600 millones en los países de la CELAC. ${ }^{64}$

El desarrollo de la relación entre ambas regiones ha experimentado distintas etapas a lo largo de su historia. Hasta mediados de los años noventa, las relaciones de la UE con los países latinoamericanos se limitaban a acuerdos de cooperación, asistencia financiera y tecnológica, y preferencias comerciales en el marco del sistema de preferencias generalizadas (SPG). En la actualidad, la política europea de desarrollo hacia ALC descansa sobre tres pilares: el diálogo político, los programas de desarrollo y los aspectos comerciales y económicos de la relación birregional.

Efectivamente, la idea fuerza del diálogo ha sido un eje esencial de la relación birregional. Parte fundamental de la asociación entre la UE y ALC ha sido la creación de una red de acuerdos comerciales. La UE es el mayor inversionista, el mayor cooperante y el segundo socio comercial de ALC hasta 2014, en que China la desplazó como el segundo socio comercial de la región, detrás de Estados Unidos.

Pese a las grandes expectativas depositadas en el proceso birregional, especialmente a partir de la primera Cumbre UEALC, celebrada en Río de Janeiro en junio de 1999, el nivel de relaciones mantenido hasta el presente entre UE y ALC resulta manifiestamente insatisfactorio. Ninguna parte parece haber satisfecho sus iniciales expectativas. Quizá la relación birregional se construyó a partir de premisas no siempre ajustadas

${ }^{64}$ Müller, art. cit., p. 51. 
a la realidad. Como bien señala José Antonio Alonso, ambas partes partieron de manejar expectativas sobredimensionadas respecto de la que tenían enfrente, lo que llevó a demandar "de la otra parte algo que aquella no está en condiciones de ofrecer", al exagerarse las reales potencialidades del otro. Mientras AL esperaba más de Europa en cuanto a cooperación, Europa esperaba mayores compromisos políticos $\mathrm{y}$, mientras tanto, las dos partes buscaban, sin obtenerlo, una mayor apertura de los mercados de aquellos bienes y servicios que más le interesaban. Más allá de logros parciales, existe la percepción de que no han alcanzado el rango que sería deseable. Entre las razones que pueden explicar este resultado está "el asimétrico interés con que cada parte contemplaba las relaciones mutuas: mientras Europa era muy importante para América Latina, esta última era una región de interés menor para Europa. La asimetría señalada se expresaba no sólo en el ámbito comercial, también en otros capítulos de las relaciones mutuas". ${ }^{65}$ Según Malamud, "esta situación se verá reforzada por el hecho de que mientras existe una mayor coordinación entre los países europeos en materia de política exterior, los gobiernos latinoamericanos acuden a la cita sin prácticamente ninguna negociación previa. No sólo eso, en algunos puntos acuden sumamente divididos". ${ }^{66}$ En cualquier caso, parece indiscutible, a juicio de Torrent, que -en cuanto a su concepción-, la política de la UE hacia ALC ha estado completamente fuera de "foco" y de establecimiento de prioridades. ${ }^{67}$

A pesar de los esfuerzos de las Cumbres Alc-Ue (19992017) parece realista constatar que no se haya podido avanzar de la forma que se esperaba, con relaciones más intensas y sustantivas entre ambas regiones. Las relaciones están "anegadas de retrocesos más que de avances” y, sobre todo, repletas de nuevos intentos por encontrar otros caminos para

65 Alonso, art. cit., p. 96.

66 Malamud, art. cit., p. 5.

67 Torrent, art. cit., p. 55 . 
acomodar la cooperación entre las dos regiones. No se puede pensar que existe una sólida cooperación ALC-UE; tampoco, en un futuro próximo, hay algo que permita decir que, por fin, los dirigentes europeos y latinoamericanos han encontrado la "fórmula mágica" que les permita afrontar sus relaciones en términos de resultados concretos, tal como señala Müller. ${ }^{68}$

El balance general que puede hacerse de las relaciones entre la UE y ALC "está lleno de claroscuros, pues los avances en aspectos concretos de las relaciones, en materia de diálogo político, cooperación y relaciones comerciales, se ve empañado por la ausencia de una estrategia global adaptada a las nuevas realidades e intereses, con lo que se pierde, se diluye o no tiene el efecto deseado una parte significativa de esos avances". 69

En ninguno de los tres pilares se han tratado algunos de los que son o deberían ser temas clave de las relaciones UEALC, como, por ejemplo, gestión de la deuda externa, inestabilidad cambiaria, protección de inversiones, migraciones, cooperación educativa. En cuanto a sus efectos, los resultados han sido muy pobres, ya no desde el punto de vista del desarrollo y la mejora de las condiciones económicas, sociales y políticas en ALC, sino desde el de la propia influencia europea en la región. ${ }^{70}$

Existe la percepción de que el enfoque tradicional con el que se han abordado las relaciones entre la UE y ALC exige una renovación profunda. El enfoque, basado en la preferencia por el diálogo con los esquemas de integración subregional, la insistencia en la cohesión social como elemento central de la agenda y el carácter gubernamental del diálogo parecen necesitados de revisión. Frente a esta visión, se aboga por construir "una relación más equilibrada, con capacidad de proyección global, basada en los intereses comunes y ca-

${ }^{68}$ Müller, art. cit., p. 8.

${ }^{69}$ Arenal, 2010, art. cit., p. 51.

70 Torrent, art. cit., pp. 53-56. 
paz de construir consensos en entornos más complejos y heterogéneos en cada una de las partes". ${ }^{71}$

En este contexto, deben tenerse en cuenta los cambios ocurridos a nivel internacional, así como en Europa y ALC en los últimos años, entre los cuales se considera muy relevante la presencia de otras potencias globales que actúen en la región latinoamericana-como China-que permite a los países de ALC una mayor diversificación de sus estrategias internacionales. En este nuevo escenario, las relaciones son mucho más complejas que en el pasado y menores las posibilidades de hacer realidad la Asociación Estratégica Birregional. En todo caso, es necesario que tanto la UE como la ALC se replanteen de forma operativa lo que quieren una de la otra, pues sólo sobre esa base será posible avanzar de manera sólida en las relaciones entre ambas regiones.

Concluimos el trabajo con una idea sobre la que nos hemos ido convenciendo a medida que avanzábamos en su elaboración: a pesar de los elementos de incertidumbre sobre las relaciones birregionales, en nosotros prevalece la certeza de que los vínculos construidos entre Eu y ALC son sólidos, profundos y mutuamente beneficiosos, y que con las debidas dosis de creatividad, flexibilidad e inteligencia, las relaciones birregionales puede seguir profundizándose en beneficio de los pueblos a ambos lados del Atlántico. En este sentido, quizás se pueda afirmar que no sólo basta con el empeño individual de los Estados para afianzar la asociación birregional y que ésta dé los frutos que debiera, sino que hace falta también que las altas instancias cooperen y sean conscientes de la relevancia que tienen América Latina y el Caribe como actores emergentes en las relaciones internacionales.

${ }^{71}$ Alonso, art. cit., pp. 97-98. 


\section{REFERENCIAS BIBLIOGRÁFICAS}

Alemany, Cecilia, "Mecanismos de diálogo Unión Europea-América Latina”, en Christian Freres et al. (ed.), ¿Sirve el diálogo politico entre la Unión Europea y América Latina?, Madrid, Fundación Carolina CeALCI, 2007, pp. 43-62.

Alonso, José Antonio, "Hacia una nueva estrategia ue-América Latina: notas para el debate", en Foro eurolatinoamericano de centros de análisis. Diálogo UE-ALC. Debate y conclusiones, Madrid, Fundación Carolina, 2010, pp. 89-103.

Arenal, Celestino del, Las relaciones entre la ue y América Latina: ¿abandono del regionalismo y apuesta por una nueva estrategia de carácter bilateralista?, Documento de Trabajo 36/2009, Madrid, Real Instituto El Cano, 2009.

Arenal, Celestino del, "Balance de la asociación estratégica entre la Unión Europea (UE) y los países de ALC", en Foro eurolatinoamericano de centros de análisis. Diálogo UE-ALC. Debate y conclusiones, Madrid, Fundación Carolina, 2010, pp. 25-55.

Comisión Europea, La asociación estratégica entre la Unión Europea, América Latina y el Caribe: un compromiso común, Luxemburgo, Oficina de Publicaciones Oficiales de las Comunidades Europeas, 2008.

Comisión Económica para América Latina y el Caribe (CEPAL), La inversión extranjera directa en América Latina y el Caribe 2018, Santiago de Chile, 2018 a.

Comisión Económica para América Latina y el Caribe (CEPAL), La Unión Europea y América Latina y el Caribe: estrategias convergentes y sostenibles ante la coyuntura global, LC/TS.2018/56/Rev.1, Santiago de Chile, 2018b.

Díaz Barrado, Cástor Miguel, "América Latina-Caribe y Unión Europea: propuestas para una difícil articulación de la cooperación en la primera mitad del siglo xxi", Documento de Investigación 27/2018, Instituto Español de Estudios Estratégicos (IEEE), 2018.

Durán Lima, José E. et al., La cooperación entre América Latina y la Unión Europea: una asociación para el desarrollo, Santiago de Chi- 
le, Comisión Económica para América Latina y el Caribe (CEPAL), 2013.

European Union External Action, "Relaciones UE-CELAC", Bruselas, 16 de julio de 2018.

Freres, Christian, “¿De las declaraciones a la asociación birregional? Perspectivas de las cumbres entre la Unión Europea y América Latina y el Caribe”, Revista Nueva Sociedad, núm. 189, 2004, pp. 110-124.

Freres, Christian y José Antonio Sanahuja, "Hacia una nueva estrategia en las relaciones Unión Europea-América Latina” (pp. 23-104), en C. Freres y J.A. Sanahuja (coords.), América Latina y la Unión Europea. Estrategias para una asociación necesaria, Barcelona, Icaria, 2006.

Freres, Christian et al. (ed.), ¿Sirve el diálogo político entre la Unión Europea y América Latina?, Madrid, Fundación Carolina CeALCI, 2007.

Levi Coral, Michel, "El diálogo político como pilar de las relaciones entre la Unión Europea y América Latina: reflexiones sobre su desarrollo y contenido", Oasis, núm. 12, Centro de Investigaciones y Proyectos Especiales, cIPE, Facultad de Finanzas, Gobierno y Relaciones Internacionales. Universidad Externado de Colombia, 2007, pp. 483-493.

Malamud, Carlos, Las relaciones entre la Unión Europea y América Latina en el siglo XXI: entre el voluntarismo y la realidad, Documento de Trabajo núm. 6, Plataforma Democrática, 2010.

Martín, Carlos D., "Las relaciones América Latina-Unión Europea: antecedentes de la importancia e institucionalización del diálogo político", Revista de Ciencia Política, vol. xxıI, núm. 2, 2002, pp. 46-64.

Molano-Cruz, Giovanni (comp.), La Unión Europea en América Latina y el Caribe (1945-2012). Lógicas y políticas de un actor global, Bogotá, Universidad Sergio Arboleda, 2015.

Müller, Gustavo G. et al., La Asociación Estratégica UE-América Latina: situación actual y caminos futuros, Bruselas, Parlamento Europeo, Dirección General de Políticas Exteriores, 2017.

OCDE/CEPAL/CAF, Perspectivas económicas de América Latina 2016. Hacia una nueva asociación con China, París, OECD Publishing, 2015. 
RuAno, Lorena, "La Unión Europea y América Latina: Breve historia de la relación birregional", Revista Mexicana de Política Exterior, núm. 112, 2018, pp. 69-87.

SAnahuja, José Antonio, "Un diálogo estructurado y plural. La dimensión institucional de las relaciones Unión Europea-América Latina", Revista Nueva Sociedad, núm. 189, 2004, pp. 80-96.

Sanahuja, José Antonio, "La efectividad de la cooperación al desarrollo entre la Unión Europea y América Latina: balance y perspectivas", Parlamento Europeo, Dirección General de Políticas Exteriores de la Unión, Nota de Información, EXPO/B/ AFET/2007/48, 2008.

Sanahuja, José Antonio, Hacia un nuevo marco de relaciones entre la Unión Europea y América Latina y el Caribe, Hamburgo: Fundación EU-LAC, 2013.

Sistema Económico Latinoamericano y del Caribe (SELA), "Las relaciones económicas recientes de América Latina y el Caribe con la Unión Europea en vísperas de la Cumbre de Madrid", SP/ RR-REALCUE-VICBM/DT Nº 2-10, Caracas, Venezuela, 2010.

Torrent, Ramón, "Las relaciones Unión Europea-América Latina en los últimos diez años: el resultado de la inexistencia de una política. Un análisis empírico y esperanzado”, UNU-CRIs Occasional Papers 0-2005/10, Barcelona, Eularo/obreal, 2005.

Tremolada, Eric, “¿Los pilares que soportan la relación de la Unión Europea con América Latina contribuyen a su desarrollo?” (pp. 193-208), en Joaquín Roy (comp.), Después de Santiago: Integración Regional y Relaciones Unión Europea-América Latina, The Jean Monnet Chair, University of Miami Miami-Florida European Union Center, 2013. 
